\title{
PRACTICE INSIGHTS
}

\section{Key Articles and Guidelines Relative to Intensive Care Unit Pharmacology-2004}

\author{
Brian L. Erstad, Pharm.D., FCCM, FCCP, FASHP, Steven J. Martin, Pharm.D., FCCP, FCCM, \\ Gretchen M. Brophy, Pharm.D., FCCP, FCCM, Curtis E. Haas, Pharm.D., FCCP, \\ Judith Jacobi, Pharm.D., FCCM, FCCP, Lynda S. Welage, Pharm.D., FCCP, and \\ Michael C. Thomas, Pharm.D.
}

Compilations of key articles and guidelines in a particular clinical practice area are useful not only to clinicians who practice in that area, but to all clinicians. We compiled pertinent articles and guidelines pertaining to drug therapy in the intensive care setting from the perspective of actively practicing critical care pharmacists. This document differs from the original 2002 version in that a broader assembly of intensive care practitioners was involved in the compilation.

Key Words: pharmacology, intensive care unit, ICU, critical care, key articles, guidelines.

(Pharmacotherapy 2005;25(4):585-610)

\section{OUTLINE}

Pharmacotherapy in the Intensive Care Unit

Acid-Base Disorders

Acute Respiratory Distress Syndrome

Alcohol Withdrawal

Cardiovascular Conditions

Endocrine Conditions

Fever

Gastrointestinal Conditions

Hematology

Infection

From the Department of Pharmacy Practice and Science, College of Pharmacy, University of Arizona, Tucson, Arizona (Dr. Erstad); the Department of Pharmacy Practice, College of Pharmacy, University of Toledo, Toledo, Ohio (Dr. Martin); the Medical College of Virginia, Virginia Commonwealth University, Richmond, Virginia (Dr. Brophy); the Department of Pharmacy Practice, School of Pharmacy and Pharmaceutical Sciences, State University of New York at Buffalo, Buffalo, New York (Dr. Haas); Methodist Hospital-Clarian Health, Indianapolis, Indiana (Dr. Jacobi); the College of Pharmacy, University of Michigan, Ann Arbor, Michigan (Dr. Welage); and Munson Medical Center, Traverse City, Michigan (Dr. Thomas).

Address reprint requests to Brian L. Erstad, Pharm.D., FCCM, FASHP, FCCP, 1703 East Mabel Street, Department of Pharmacy Practice and Science, College of Pharmacy, University of Arizona, Tucson, AZ 85721-0207; e-mail: erstad@pharmacy.arizona.edu.
Neurosurgery and Neurology

Nutrition

Sedation, Analgesia, Delirium, and Neuromuscular

Blockade

Toxicology

Vasoactive Agents

Economic Benefits of Intensive Care Unit Pharmacy

Services

Medication Errors and Adverse Drug Events in the

Intensive Care Unit

The original compilation of key articles and guidelines pertaining to intensive care unit (ICU) pharmacology was published in 2002 (Pharmacotherapy 22;12:1594-610). That compilation was primarily from the perspective of the general ICU practice of the primary author (BLE); therefore, certain topics (e.g., stroke) were not covered to a significant degree. This document was compiled by selected members of the Critical Care Practice and Research Network (PRN) of the American College of Clinical Pharmacy. Therefore, this bibliography contains a more diverse range of articles reflective of the authors' interest areas and practice settings. In addition, we compiled this version using an evidence-based classification system for research investigations (Eastern 
Association for the Surgery of Trauma [EAST] Ad Hoc Committee on Practice Management Guideline Development. Utilizing evidencebased outcome measures to develop practice management guidelines: a primer; available from http://www. east.org/tpg.html). This classification system is as follows: class I, randomized controlled trials; class II, prospective trials and retrospective studies with reliable data (e.g., casecontrol studies); and class III, retrospective studies and expert opinion.

The information in this compilation should be particularly useful for trainees and relatively new practitioners in the critical care setting. However, we hope it also might serve as a useful template for experienced clinicians who have contemplated a similar undertaking in their practice areas.

The development process began with a preliminary discussion of a potential revision of the original article by several Critical Care PRN members. These members were subsequently sent a copy of the original article and asked for input regarding possible format changes (e.g., disease- vs drug-based approach) and choice of sections for authorship. Additional authors from the Critical Care PRN were then invited to participate based on their recognized areas of expertise in sections not chosen by members of the initial group. Once written, the sections were compiled and reviewed by all authors to help ensure appropriate article selections and summaries. We could not include every published paper we considered important to critical care pharmacotherapy; however, we compiled what we believed were the most representative articles addressing the selected critical care topics.

As in the original version, this bibliography is divided into three general sections. The first focuses on landmark and contemporary pivotal articles and guidelines pertaining to pharmacotherapy in the ICU setting. When these were not available in a specific clinical area, comprehensive reviews or articles were chosen that have generated substantial discussion among ICU practitioners. The second section focuses on literature pertaining to the economic justification of ICU pharmacy services (both supporting and opposing) or, more specifically, the justification of pharmacists in the critical care setting. The final section focuses on articles pertaining to medication errors and adverse drug events in the ICU. Many of the articles pertaining to adverse drug events in the institutional setting apply to the ICU, but we chose articles specific to the ICU.

\section{Pharmacotherapy in the Intensive Care Unit}

Acid-Base Disorders

Gehlbach BK, Schmidt GA. Bench-to-bedside review: treating acid-base abnormalities in the intensive care unit: the role of buffers. Crit Care 2004;8:259-65.

This article reviews the pharmacologic buffering therapy available to treat metabolic acidosis in the ICU. The agents reviewed include sodium bicarbonate, Carbicarb (an equimolar solution of sodium bicarbonate and sodium carbonate), tromethamine, dichloroacetate, thiamine, and volume expanders. Evidence for the clinical efficacy of these buffering agents and correction of arterial $\mathrm{pH}$ are also reviewed.

Kellum JA. Determinants of blood pH in health and disease. Crit Care 2000;4:6-14.

The practice of critical care requires an advanced understanding of acid-base physiology. This article reviews three variables that regulate blood pH: carbon dioxide, relative electrolyte concentrations, and total weak acid concentrations. It provides pathophysiologic mechanisms by organ system and differential diagnoses of metabolic acid-base disorders.

Adrogue HJ, Madias NE. Management of lifethreatening acid-base disorders: part I. N Engl J Med 1998;338:26-34.

This is the first of a two-part review article that focuses on consequences of severe acidemia. It reviews the management of metabolic acidosis (lactic acidosis, diabetic ketoacidosis, alcoholic ketoacidosis, methanol and ethylene glycol intoxications, aspirin intoxication, toluene exposure, bicarbonate loss, renal failure and dilutional acidosis) and respiratory acidosis.

Adrogue HJ, Madias NE. Management of lifethreatening acid-base disorders: part II. N Engl J Med 1998;338:107-11.

Part II of the two-part article reviews the adverse cardiovascular, respiratory, metabolic and cerebral consequences of severe alkalemia. Management strategies for metabolic alkalosis, respiratory alkalosis, pseudorespiratory alkalosis, and mixed alkaloses are discussed.

Acute Respiratory Distress Syndrome

Ware LB, Matthay MA. The acute respiratory distress syndrome. N Engl J Med 2000;342: 1334-49. 
In recent years, advances have been made in the treatment and general understanding of acute respiratory distress syndrome. This comprehensive review article addresses the definitions, epidemiology, pathogenesis, and treatment of the syndrome. The authors concluded that future trials targeting new ventilatory strategies or pharmacotherapy may further demonstrate a reduction in mortality.

The Acute Respiratory Distress Syndrome (ARDS) Network Authors. Ketoconazole for early treatment of acute lung injury and acute respiratory distress syndrome: a randomized controlled trial. JAMA 2000;283:1995-2002.

Ketoconazole possesses antiinflammatory properties that may be beneficial for the treatment or prevention of early acute lung injury or acute respiratory distress syndrome. In this randomized controlled trial, no significant differences in survival, duration of mechanical ventilation, or lung function were found between ketoconazole $400 \mathrm{mg} /$ day (117 patients) and placebo (117 patients). This article is important because it provided firm evidence that ketoconazole is not useful for treatment of acute respiratory distress syndrome. (Class I)

\section{Alcohol Withdrawal}

Dappen JB, Gache P, Landry U, et al. Symptomtriggered versus fixed-schedule doses of benzodiazepine for alcohol withdrawal: a randomized treatment trial. Arch Intern Med 2002;162:1117-21.

This randomized, double-blind, controlled trial evaluated the potential benefits of individualized therapy compared with fixed-schedule dosing of benzodiazepine for prevention of alcohol withdrawal. Benzodiazepine therapy was administered either as a fixed dose or based on the patient's score on the revised Clinical Institute Withdrawal Assessment-Alcohol, using a placebo-controlled, double-dummy design. Symptom-triggered therapy resulted in a significant reduction in dosage and duration of therapy compared with the fixed-dosage regimen. The authors concluded that symptom-triggered therapy can shorten detoxification time and reduce unnecessary drug administration without compromising safety. The ability to extrapolate these findings to critically ill patients experiencing alcohol withdrawal is unknown. (Class I)

D’Onofrio G, Rathlev NK, Ulrich AS, Fish SS,
Freedland ES. Lorazepam for the prevention of recurrent seizures related to alcohol. N Engl J Med 1999;340:915-19.

This prospective, randomized, double-blind, placebo-controlled trial evaluated whether lorazepam prevented recurrent seizures in chronic alcoholics. One hundred eighty-six patients with a witnessed generalized seizure, known to have had a drink within 72 hours of seizure onset, received either lorazepam or placebo in addition to routine care. Patients were observed for 6 hours for evidence of recurrent alcohol-related seizures. The risk of subsequent seizures was significantly higher in the placebo group (odds ratio [OR] 10.4, 95\% confidence interval [CI] 3.6-30.2). Based on these findings, benzodiazepines appear to be effective agents for the prevention of recurrent alcohol withdrawal seizures. (Class I)

Mayo-Smith MF, for the American Society of Addiction Medicine Working Group on Pharmacological Management of Alcohol Withdrawal. Pharmacological management of alcohol withdrawal: a meta-analysis and evidencebased practice guideline. JAMA 1997;278:144-51.

This article presents an evidence-based guideline for the pharmacologic management of alcohol withdrawal based on a meta-analysis of the literature. Six prospective, controlled trials, involving five different agents, demonstrated that benzodiazepines are the most efficacious drug therapy for reducing signs and symptoms of alcohol withdrawal. The superiority of one benzodiazepine over another was not definitively demonstrated. The use of a structured assessment, such as the revised Clinical Institute Withdrawal Assessment-Alcohol, is recommended for evaluating and monitoring patients at risk for alcohol withdrawal. Treatment guidelines and a discussion regarding the efficacy of potential adjunctive options are provided. This guideline did not specifically address the management of alcohol withdrawal in critically ill patients.

\section{Cardiovascular}

The following compilations of key articles and guidelines pertaining to arrhythmias, acute coronary syndromes, and hypertension have been covered in previous issues of this journal:

Dobesh PP, Brouse SD, Johnson DC, et al. Key articles and guidelines relative to treatment of patients with acute coronary syndromes. Pharmacotherapy 2004;24:105-44. 
Cheng JW, Frank L, Garrett SD, Lu Y, Sanoski CA, White CM. Key articles and guidelines in pharmacotherapeutic management of arrhythmias. Pharmacotherapy 2004;24:248-79.

de Denus S, Hardy AM, Olson KL, Robinette B. Key articles and guidelines in the management of hypertension. Pharmacotherapy 2004;24:1385-99.

\section{Arrhythmias}

Karth GD, Geppert A, Neunteufl T, et al. Amiodarone versus diltiazem for rate control in critically ill patients with atrial tachyarrhythmias. Crit Care Med 2001;29:1149-53.

Atrial arrhythmias are common in critically ill patients. In this prospective, randomized trial, two different dosage regimens of amiodarone were compared with diltiazem in 60 patients with new-onset atrial tachyarrhythmias (95\% had atrial fibrillation). At least $50 \%$ of patients in all three groups achieved more than a 30\% rate reduction within 4 hours $(\mathrm{p}=\mathrm{NS})$. Over a 24hour period, patients receiving diltiazem demonstrated a significantly greater reduction in heart rate than those in either amiodarone group $(\mathrm{p}<0.01)$. However, frequency of hypotension was higher in the diltiazem group $(p<0.01)$, often requiring withdrawal of treatment. The authors concluded that both drugs provided effective rate control in patients with atrial tachyarrhythmias; however, amiodarone may be better tolerated in hemodynamically unstable patients. (Class I)

Hughes M, Binning A. Intravenous amiodarone in intensive care: time for a reappraisal? Intensive Care Med 2000;26:1730-9.

The authors cite drug-induced acute pulmonary toxicity in critically ill patients as a reason to reevaluate the use of amiodarone in the ICU. This article reviews dosing, pharmaco-dynamics, pharmacokinetics, drug interactions, efficacy, and toxicity of amiodarone. The authors concluded that there are alternatives to amiodarone for many patients, and caution should be exercised when the drug is used in the treatment of critically ill patients.

\section{Heart Failure}

Publication Committee for the VMAC Investigators. Intravenous nesiritide vs nitroglycerin for the treatment of decompensated congestive heart failure: a randomized controlled trial. JAMA 2002;287:1531-40.

The Vasodilation in the Management of Acute
Congestive Heart Failure (VMAC) trial enrolled 489 patients with New York Heart Association class III or IV heart failure at 55 medical centers in the United States. The primary end points were changes in pulmonary capillary wedge pressure (PCWP) and patient-reported dyspnea scores at 3 hours. Secondary outcome measures were PCWP changes at 24 hours, dyspnea scores, global clinical status, and safety. Patients were initially stratified based on presence or absence of a right heart catheter. At the end of 3 hours, the mean change in PCWP was $-5.8 \mathrm{~mm} \mathrm{Hg}$ for patients receiving nesiritide, $-3.8 \mathrm{~mm} \mathrm{Hg}$ for those receiving nitroglycerin, and $-2 \mathrm{~mm} \mathrm{Hg}$ for those receiving placebo $(\mathrm{p}<0.05$ for comparison of nesiritide with nitroglycerin and placebo). Dyspnea scores were significantly improved when nesiritide was compared with placebo but was no different when compared with nitroglycerin. Global clinical status was similar in all groups $(\mathrm{p}=\mathrm{NS})$. After 24 hours, PCWP changed by $-8.2 \mathrm{~mm} \mathrm{Hg}$ in the nesiritide group compared with $-6.3 \mathrm{~mm} \mathrm{Hg}$ in the nitroglycerin group $(\mathrm{p}=0.04)$. Dyspnea and global clinical status were not significantly different. Adverse events were more common in the nitroglycerin group than the nesiritide group $(\mathrm{p}<0.001)$. Headache and pain were reported most often. Rates of hypotension, ischemic events, and arrhythmias were similar between the groups. However, duration of hypotension was significantly longer with nesiritide ( $2.2 \mathrm{hrs})$ than nitroglycerin (0.7 hrs $)(p=0.002)$. This trial provides additional evidence for the conclusions of a previous trial (see Colucci WS, Elkayam U, Horton DP, et al. Intravenous nesiritide, a natriuretic peptide, in the treatment of decompensated congestive heart failure. N Engl J Med 2000;343:246-53) that nesiritide is a useful addition to standard therapy in the treatment of patients with decompensated heart failure. (Class I)

Heart Failure Society of America. Heart Failure Society of America (HFSA) practice guidelines. HFSA guidelines for management of patients with heart failure caused by left ventricular systolic dysfunction-pharmacological approaches. J Card Fail 1999;5:357-82.

These guidelines present a graded, evidencebased approach to managing heart failure. They provide an overview of public health concerns, pathophysiology, and therapy. The guidelines consider angiotensin-converting enzyme inhibitors and diuretics fundamental aspects of heart failure treatment. Graded recommendations are made 
for adding adrenergic receptor blockers, digoxin, anticoagulation and antiplatelet agents, angiotensin receptor blockers, antiarrhythmics, and aldosterone antagonists. Treatment of myocarditis is also reviewed.

\section{Hypertension}

Haas CE, LeBlanc JM. Acute postoperative hypertension: a review of therapeutic options. Am J Health-Syst Pharm 2004;61:1661-75.

This article reviews the underlying pathophysiology, hemodynamics, potential complications, and treatment options for acute postoperative hypertension. The authors present the pharmacology, clinical response, and supporting evidence for the vasodilators and $\beta$ blockers commonly used in the management of acute postoperative hypertension, along with the significant limitations of the current literature.

\section{Fluids}

The SAFE Study Investigators. A comparison of albumin and saline for fluid resuscitation in the intensive care unit. N Engl J Med 2004;350: 2247-56.

This multicenter, randomized, double-blind comparison of $4 \%$ albumin and normal saline for resuscitation of patients admitted to the ICU enrolled 6997 patients; 28-day mortality was the primary end point. No statistically significant differences were observed in death (relative risk [RR] $0.99,95 \%$ CI 0.91-1.09) or any of the secondary end points under study. (Class I)

Cooper DJ, Myles PS, McDermott FT, et al. Prehospital hypertonic saline resuscitation of patients with hypotension and severe traumatic brain injury. JAMA 2004;291:1350-7.

This was a double-blind, randomized, controlled trial involving 229 hypotensive patients (systolic blood pressure $<100 \mathrm{~mm} \mathrm{Hg}$ ) who experienced traumatic brain injury (Glasgow Coma Scale score $<9$ ). In addition to conventional resuscitation procedures employed by paramedics, patients were randomized to receive rapid intravenous infusions $(250 \mathrm{ml})$ of either $7.5 \%$ sodium chloride or Ringer's lactate solution. Patients in both groups were given additional crystalloid or colloid fluids based on protocol. The major outcome measure was the extended Glasgow Outcome Score at 6 months. Survival rates were similar with $7.5 \%$ sodium chloride and Ringer's lactate $(55 \%$ and $50 \%$, respectively, at discharge, $\mathrm{p}=0.32 ; 55 \%$ and $47 \%$, respectively, at
$6 \mathrm{mo}, \mathrm{p}=0.23$ ). Similarly, no significant difference was noted between the groups based on neurologic function $(p=0.96)$. The use of the Glasgow Outcome Score as a primary outcome measure in this study is somewhat of a concern in that it is more reflective of unfavorable rather than favorable outcomes. However, as mentioned by the investigators in their response to this criticism (JAMA 2004;291:2944-5), a much larger sample would have been needed to investigate the effects of the solutions based on a favorable outcome measure. (Class I)

Sort P, Navasa M, Arroyo V, et al. Effect of intravenous albumin on renal impairment and mortality in patients with cirrhosis and spontaneous bacterial peritonitis. N Engl J Med 1999;341:403-9.

Renal impairment, as a result of cytokine release and decreased arterial blood volume, is common in patients with spontaneous bacterial peritonitis. Albumin may prevent renal dysfunction through its effects on volume expansion and possibly other mechanisms. In this study, 126 patients with cirrhosis and spontaneous bacterial peritonitis were randomized to cefotaxime or cefotaxime plus albumin. In the control group, $33 \%$ of patients developed renal impairment, versus $10 \%$ in the albumin group $(p=0.002)$. Mortality in the hospital and at 3 months was significantly lower in albumintreated patients than in control patients $(p=0.01$ and $\mathrm{p}=0.03$, respectively). This trial is important because it is one of the few well-controlled trials demonstrating a positive benefit of albumin beyond its effects on surrogate end points. (Class I)

Choi PTL, Yip G, Quinonez LG, Cook DJ. Crystalloids vs. colloids in fluid resuscitation: a systematic review. Crit Care Med 1999;27: 200-10.

This review of 17 randomized trials compared isotonic crystalloids with colloids for volume resuscitation in 814 adult patients. No differences were noted in mortality, pulmonary edema, or length of hospital stay. However, a subgroup analysis revealed decreased mortality with crystalloid administration in patients who experienced trauma (RR 0.39, 95\% CI 0.17-0.89). The authors concluded that more research is necessary to resolve the ongoing controversy regarding the most appropriate and effective method for fluid resuscitation.

Cochrane Injuries Group Albumin Reviewers. Human albumin administration in critically ill 
patients: systematic review of randomised controlled trials. BMJ 1998;317:235-40.

In this systematic review of 30 randomized, controlled trials involving 1419 critically ill patients, albumin administration was associated with one death for every 17 patients treated for hypovolemia, burns, or hypoalbuminemia. Although a significant difference in mortality after albumin administration was not found in each of the categories, the pooled relative risk of albumin-associated death was significant (RR $1.68,95 \%$ CI 1.26-2.23). This review, as well as an earlier review in the same journal (Schierhout G, Roberts I. Fluid resuscitation with colloid or crystalloid solutions in critically ill patients: a systematic review of randomised trials. BMJ 1998;316:961-4), fueled the colloid-crystalloid debate by pushing the limits of meta-analytic technique.

Bickell WH, Wall MJ, Pepe PE, et al. Immediate versus delayed fluid resuscitation for hypotensive patients with penetrating torso injuries. N Engl J Med 1994;331:1105-9.

Previous studies in animal models have suggested that the volume of intravenous fluid resuscitation may contribute to intraoperative bleeding. In this prospective study, trauma patients with hypotension were randomized to immediate (309 patients) or delayed (289 patients) resuscitation. The primary objective was to determine if the rate of survival would improve when intravenous fluid resuscitation was withheld until the time of surgery. The overall rate of survival was significant in the delayed versus immediate resuscitation group ( $70 \%$ vs $62 \%, \mathrm{p}=0.04$ ). Postoperative complications (acute respiratory distress syndrome, sepsis syndrome, acute renal failure, coagulopathy, wound infection, and pneumonia) also tended to occur less often when fluid administration was delayed, although the difference was not significant. (Class I)

\section{Endocrine Conditions}

Hamrahian AH, Oseni TS, Arafah BM. Measurements of serum free cortisol in critically ill patients. N Engl J Med 2004;350:1629-38.

This prospective study assessed baseline serum total cortisol, cosyntropin-stimulated serum total cortisol, aldosterone, and free cortisol concentrations in 60 critically ill patients and 33 healthy volunteers. Critically ill patients were stratified into two groups based on serum albumin concentration. Baseline and cosyntropinstimulated total cortisol concentrations were significantly lower in patients whose albumin concentrations were $2.5 \mathrm{~g} / \mathrm{dl}$ or less. However, average baseline free cortisol concentrations were not different between the two groups of critically ill patients. Free cortisol concentrations were more than 8 times higher in the critically ill patients than in the healthy volunteers. The authors concluded that caution should be used in interpreting total cortisol concentrations in critically ill patients with hypoalbuminemia, and that measuring serum free cortisol concentrations may prevent unnecessary use of glucocorticoids. (Class II)

Van den Berghe G, Wouters PJ, Bouillon R, et al. Outcome benefit of intensive insulin therapy in the critically ill: insulin dose versus glycemic control. Crit Care Med 2003;31:359-66.

This is a secondary analysis of a previously published report demonstrating the efficacy of intensive insulin therapy in reducing morbidity and mortality among critically ill patients. The authors focused their assessment on the feasibility and safety of intensive insulin therapy, identification of factors that determine insulin requirements, and determination of the impact of glycemic control versus the amount of exogenous insulin infused on morbidity and mortality measures. The analysis demonstrated that it is safe and feasible to maintain blood glucose levels of $80-110 \mathrm{mg} / \mathrm{dl}$ using a titration algorithm. Independent factors influencing insulin requirements were body mass index, history of diabetes mellitus, reason for ICU admission, presence of hyperglycemia on admission, caloric intake, and duration of ICU stay. Multivariate logistic regression analysis revealed that lower blood glucose level rather than insulin dosage was related to reduced morbidity and mortality. Among patients whose ICU stay exceeded 5 days, post hoc analysis revealed a gradual decrease in risk of death with decreasing blood glucose level. Patients whose blood glucose was maintained at intermediate levels of $110-150 \mathrm{mg} / \mathrm{dl}$ had worse outcomes than those whose levels were normal. (Class II)

Cooper MS, Stewart PM. Corticosteroid insufficiency in acutely ill patients. N Engl J Med 2003;348:727-34.

This review eloquently summarizes the physiology of corticosteroid response to acute illness by contrasting both the appropriate and 
inappropriate hypothalamic-pituitary-adrenal axis response during acute illness. The authors describe the clinical features of hypoadrenalism in patients with acute illness. They also provide a useful algorithm for evaluating adrenal corticosteroid function in critically ill patients based on random cortisol levels and/or the corticotropin stimulation test. Recommendations are provided for steroid replacement during acute illness in patients with adrenal insufficiency, including those who previously received corticosteroids.

Van den Berghe G, Wouters P, Weekers F, et al. Intensive insulin therapy in critically ill patients. N Engl J Med 2001;345:1359-67.

This prospective, randomized, controlled trial involving 1548 mechanically ventilated surgical patients with hyperglycemia evaluated the effects of intensive insulin therapy or conventional treatment. Goal blood glucose levels were $80-110 \mathrm{mg} / \mathrm{dl}$ with intensive insulin therapy and 180-200 mg/dl with conventional treatment. At 12 months, mortality was significantly reduced in the intensive insulin therapy group compared with the conventional treatment group $(4.6 \%$ vs $8 \%, \mathrm{p}<0.04)$. The benefits of intensive insulin therapy were most noteworthy in the patients whose ICU stay exceeded 5 days; mortality was $10.6 \%$ in that intensive insulin therapy group compared with $20.2 \%$ in the conventional treatment group $(\mathrm{p}<0.005)$. This trial also demonstrated significant reductions in morbidity (e.g., bloodstream infections, acute renal failure requiring dialysis, number of blood transfusions, critical-illness polyneuropathy, duration of mechanical ventilation, and length of ICU stay) with the use of intensive insulin therapy. (Class I)

Singer I, Oster JR, Fishman LM. The management of diabetes insipidus in adults. Arch Intern Med 1997;157:1293-301.

This comprehensive review discusses the pathogenesis, differential diagnosis, and treatment strategies for acute and chronic water deficits. Desmopressin acetate is the preferred agent for treatment of symptomatic central diabetes insipidus, whereas treatment of nephrogenic diabetes insipidus centers on the resolution of underlying conditions. The authors identified noncompliance, medical emergency, and iatrogenic inadvertence as the most common causes of unplanned treatment withdrawals.

\section{Fever}

Henker R. Evidence-based practice: fever-related interventions. Am J Crit Care 1999;8:481-9.

This review summarizes the literature regarding whether or not a fever should be treated and the effectiveness of various interventions for treating fever in critically ill patients. Although the author does not use the more traditional classifications of levels of evidence, in which level 1 is the highest, the classification used is provided and readily understandable. The review highlights the tremendous lack of data evaluating various strategies (e.g., physical cooling vs antipyretics) used to treat fever.

O'Grady NP, Barie PS, Bartlett J, et al. Practice parameters for evaluating new fever in critically ill adult patients. Crit Care Med 1998;26:392-408.

Fever in intensive care patients consumes substantial financial and medical resources. An interdisciplinary team with members from the areas of critical care, infectious diseases, and surgery developed consensus guidelines to aid in the rational, cost-conscious evaluation of a new fever. The overall aim of these evidence-based guidelines, endorsed by the Society of Critical Care Medicine and the Infectious Diseases Society of America, is to minimize unnecessary testing and facilitate prompt implementation of appropriate therapy.

\section{Gastrointestinal Conditions}

\section{Intestinal Transit}

Meissner W, Dohrn B, Reinhart K. Enteral naloxone reduces gastric tube reflux and frequency of pneumonia in critical care patients during opioid analgesia. Crit Care Med 2003;31:776-80.

This prospective, randomized, double-blind trial evaluated the efficacy of enteral naloxone (8 mg every $6 \mathrm{hrs}$ ) versus placebo in reducing gastric tube reflux and the frequency of pneumonia in 84 mechanically ventilated patients. All patients were receiving continuous infusion of fentanyl for analgesia, and the dosage requirements were not significantly different between the two groups. The median daily gastric tube reflux volumes were significantly lower in the naloxone treatment group than in the placebo group ( $54 \mathrm{vs} 129 \mathrm{ml}, \mathrm{p}=0.03$ ). The frequency of pneumonia was also significantly lower in the naloxone versus the placebo group (34.2\% vs $55.8 \%, \mathrm{p}=0.04$ ). The authors concluded that oral naloxone might be a simple and possibly preventive strategy to reduce gastric tube reflux and the frequency of pneumonia in 
fentanyl-treated, mechanically ventilated patients. (Class I)

Booth CM, Heyland DK, Peterson WG. Gastrointestinal promotility drugs in the critical care setting: a systematic review of the evidence. Crit Care Med 2002;30:1429-35.

Delayed gastric emptying is common among critically ill patients, occurring in up to $60 \%$ of those who are mechanically ventilated. Gastric hypomotility may lead to impaired nutrient delivery, high gastric residuals, and risk of aspiration. This review summarizes the data regarding the efficacy of prokinetic agents (metoclopramide, erythromycin, and cisapride) in improving gastric emptying in critically ill patients. Eight of the 10 studies reviewed demonstrated a positive effect. However, four of these studies evaluated only cisapride, which has been removed from the United States market. Although evidence supports the efficacy of prokinetic agents (erythromycin and metoclopramide) for promoting gastric emptying, data demonstrating a positive impact on patient outcome (e.g., reduced frequency of pneumonia or mortality) are lacking.

van der Spoel J, Oudemans-van Straaten H, Stoutenbeek C, Bosman R, Zandstra D. Neostigmine resolves critical illness-related colonic ileus in intensive care patients with multiple organ failure-a prospective, doubleblind, placebo-controlled trial. Intensive Care Med 2001;27:822-7.

In this double-blind, randomized, placebocontrolled trial of 30 ventilated patients with multiple organ failure, 11 of 13 responded to neostigmine treatment for critical illness-related colonic ileus; resolution of symptoms was not evident in any of the patients in the placebo group (11 neostigmine-treated patients vs 0 placebo patients, $\mathrm{p}<0.001)$. Nineteen $(79 \%)$ of 24 neostigmine-treated patients defecated, including nonresponders who were switched from the placebo group. Continuous infusion of neostigmine $(0.4-0.8 \mathrm{mg} / \mathrm{hr}$ for $24 \mathrm{hrs})$ appeared to be a well-tolerated therapy in this small sample of critically ill, mechanically ventilated patients with a colonic ileus. (Class I)

\section{Stress Ulcer Prophylaxis}

Cook DJ, Griffith LE, Walter SD, et al. The attributable mortality and length of intensive care unit stay of clinically important gastrointestinal bleeding in critically ill patients. Crit Care
2001;5:368-75.

This study uses three different strategies to estimate mortality and length of stay in the ICU attributable to clinically important upper gastrointestinal bleeding. Data from 1666 mechanically ventilated patients from two multicenter databases were used to perform the analyses. Of the 1666 patients, 59 developed clinically important gastrointestinal bleeding. Risk of death was increased in patients with bleeding, regardless of analysis strategy used; relative risk ranged from 1.8 (95\% CI 1.1-2.9) to 4.1 (95\% CI 2.6-6.5). The median length of ICU stay attributable to clinically important bleeding was 3.8-7.9 days depending on the model employed. Overall, this study demonstrates that although the frequency of clinically important gastrointestinal bleeding may be low, the patient's condition is associated with important attributable morbidity, such as a long ICU stay (4-8 days), and mortality. (Class II)

American Society of Health-System Pharmacists. ASHP therapeutic guidelines on stress ulcer prophylaxis. Am J Health-Syst Pharm 1999;56: 347-79.

Numerous articles have been published on stress ulcer prophylaxis. This comprehensive, evidence-based guideline reviews the frequency of bleeding and the efficacy of prophylaxis in intensive care patients and special populations. Although this 1999 review lacks the more recent findings, it summarizes the epidemiology and populations at risk for stress ulcers. It also evaluates the evidence regarding treatment options available at the time. A more recent article (Allen ME, Kopp BJ, Erstad BL. Am J Health-Syst Pharm 2004;61:588-96) critically reviews more recently published data on therapeutic approaches to stress ulcer prophylaxis.

Cook D, Guyatt G, Marshall J, et al. A comparison of sucralfate and ranitidine for the prevention of upper gastrointestinal bleeding in patients requiring mechanical ventilation. N Engl J Med 1998;338:791-7.

Two agents used for stress ulcer prophylaxis, ranitidine and sucralfate, were compared in 1200 mechanically ventilated, critically ill patients for prevention of clinically important upper gastrointestinal bleeding. This landmark, multicenter, randomized, double-blind, placebocontrolled study demonstrated a lower bleeding frequency in the ranitidine group than in the sucralfate group (RR 0.44 , 95\% CI $0.21-0.92$ ). 
No difference between the two groups was noted for rate of ventilator-associated pneumonia, length of ICU stay, or survival. This study demonstrates the superiority of ranitidine $(50 \mathrm{mg}$ given intravenously every $8 \mathrm{hrs}$ ) over sucralfate (1 g administered by nasogastric tube every 6 hrs) for prevention of clinically important upper gastrointestinal bleeding. (Class I)

Cook DJ, Fuller HD, Guyatt GH, et al. Risk factors for gastrointestinal bleeding in critically ill patients. N Engl J Med 1994;330:377-81.

This prospective, multicenter, observational study evaluated potential risk factors for stress ulceration in 2252 critically ill patients. Clinically important gastrointestinal bleeding occurred in $1.5 \%$ of patients. The two major independent risk factors for bleeding identified by multivariate analyses were respiratory failure (OR 15.6), and coagulopathy (OR 4.3). This study clearly highlights the importance of respiratory failure and coagulopathy as two major risk factors for stress-related mucosal bleeding. However, because the study involved only a critically ill patient population, these should not be considered the only risk factors for stressrelated mucosal bleeding. Specifically, earlier literature suggests that patients with head injury, burns, multiple trauma, sepsis, or shock may also be at risk. However, few patients with these conditions were included in the trial. (Class II)

\section{Nonvariceal Upper Gastrointestinal Bleeding}

Barkun A, Bardou M, Marshall JK, et al. Consensus recommendations for managing patients with nonvariceal upper gastrointestinal bleeding. Ann Intern Med 2003;139:843-57.

Consensus guidelines for the management of nonvariceal upper gastrointestinal bleeding were developed by a multidisciplinary panel representing 11 national societies. The guidelines recommend that institution-specific protocols be developed. Initial management should include stratification of patients into high and low risk categories for rebleeding and death on the basis of clinical, endoscopic, and prognostic factors. Early endoscopy is warranted to facilitate diagnosis and risk stratification, and to provide hemostasis in patients with stigmata suggesting high risk of rebleeding. A combination of injection and thermal coagulation provides superior endoscopic hemostasis in patients with high-risk stigmata compared with either treatment alone. High-dose intravenous therapy with a proton pump inhibitor is recommended for patients who have undergone endoscopic hemostasis. Each recommendation was graded according to the level and strength of available evidence.

Sung JJY, Chan FKL, Lau JYW, et al. The effect of endoscopic therapy in patients receiving omeprazole for bleeding ulcers with nonbleeding visible vessels or adherent clots. Ann Intern Med 2003;139:237-43.

Earlier trials demonstrated that omeprazole given as a continuous infusion is effective in preventing peptic ulcer rebleeding in patients at high risk of rebleeding (i.e., nonbleeding visible vessel or bleeding ulcers) who have undergone endoscopic hemostasis. This single-blind, randomized trial assessed whether combination therapy (endoscopy plus a proton pump inhibitor) was superior to omeprazole alone in preventing peptic ulcer rebleeding in patients with nonbleeding visible vessels or adherent clots. The probability of recurrent bleeding within 30 days was significantly less in the group receiving combination therapy $(1.1 \%)$ than in the group receiving omeprazole alone (11.6\%; $\mathrm{p}=0.009$ ). Previously published data demonstrating the efficacy of omeprazole after endoscopic hemostasis, in concert with the results of this study, emphasize that dualmodality therapy (endoscopic hemostasis plus intravenous omeprazole) is the most effective strategy for reducing the risk of rebleeding in high-risk patients. (Class I)

Levine JE, Leontiadis GI, Sharma VK, Howden CW. Meta-analysis: the efficacy of intravenous $\mathrm{H}_{2}$-receptor antagonists in bleeding peptic ulcer. Aliment Pharmacol Ther 2002;16:1137-42.

This meta-analysis was conducted to assess the efficacy of histamine ${ }_{2}\left(\mathrm{H}_{2}\right)$-receptor antagonists in the management of peptic ulcer bleeding. Pooling data from randomized placebocontrolled trials, the authors demonstrated that $\mathrm{H}_{2}$-receptor antagonists do not significantly reduce rebleeding, surgery, or death in patients with bleeding duodenal ulcers. Significant, however minor, reductions were observed in rebleeding, surgery, and death in patients with bleeding gastric ulcers (absolute risk reduction $7.2 \%, 6.7 \%$, and $3.2 \%$, respectively). Based on these data, intravenous $\mathrm{H}_{2}$-receptor antagonists should be considered of no value in patients with bleeding duodenal ulcers and of limited value in patients with bleeding gastric ulcers. 
Gisbert JP, Gonzalez L, Clvert X, et al. Proton pump inhibitors versus $\mathrm{H}_{2}$ antagonists: a metaanalysis of their efficacy in treating bleeding peptic ulcer. Aliment Pharmacol Ther 2001;15: 917-26.

This meta-analysis evaluated whether proton pump inhibitors were more effective than $\mathrm{H}_{2}$ receptor antagonists in patients with bleeding peptic ulcers. Using data from 11 international comparative, randomized trials, persistent or recurrent bleeding was noted in $6.7 \%(95 \% \mathrm{CI}$ $4.9-8.6 \%)$ of patients receiving proton pump inhibitors and in $13.4 \%$ (95\% CI $10.8-16 \%$ ) of patients treated with $\mathrm{H}_{2}$-receptor antagonists. Although this analysis demonstrates that proton pump inhibitors are more effective than $\mathrm{H}_{2}$ receptor antagonists in preventing persistent or recurrent peptic ulcer bleeding, no significant difference was seen in mortality or need for surgery.

Lau JYW, Sung JJY, Lee KKC, et al. Effect of intravenous omeprazole on recurrent bleeding after endoscopic treatment of bleeding peptic ulcers. N Engl J Med 2000;343:310-16.

This landmark, single-center, randomized, double-blind, placebo-controlled trial assessed the efficacy of intravenous omeprazole in preventing peptic ulcer rebleeding after endoscopic hemostasis. Patients with actively bleeding ulcers or ulcers with nonbleeding visible vessels received endoscopic hemostasis with epinephrine injection followed by thermocoagulation. Then, 240 patients were randomized in a double-blind fashion to receive an intravenous bolus dose of omeprazole $80 \mathrm{mg}$ followed by $8 \mathrm{mg}$ /hour continuous infusion, or placebo for 72 hours. Subsequently, all patients received oral omeprazole $20 \mathrm{mg} /$ day for 8 weeks. The frequency of rebleeding within the first 30 days was significantly reduced in the omeprazole group $(6.7 \%)$ compared with the placebo group (22.5\%). Most episodes of bleeding occurred within the first 3 days. This well-designed trial demonstrates the efficacy of omeprazole given as a high-dose continuous infusion for prevention of peptic ulcer rebleeding after endoscopic hemostasis in patients at high risk of rebleeding. (Class I)

Hematology

\section{Antithrombotics}

American College of Chest Physicians. The seventh ACCP consensus conference on antithrombotic and thrombolytic therapy: evidence- based guidelines. Chest 2004;126(suppl): 163S-696.

This report from the American College of Chest Physicians provides an extensive evidencebased review of the management of thromboembolic disorders.

\section{Blood Conservation and Transfusion}

Corwin HL, Gettinger A, Pearl RG, et al. The CRIT study: anemia and blood transfusion in the critically ill-current clinical practice in the United States. Crit Care Med 2004:32:39-52.

This prospective, multicenter, observational, cohort study of 4892 patients, conducted in 2000-2001, serves as an important historic control to compare current patterns of blood use. The patients' mean \pm SD hemoglobin level was 11 $\pm 2.4 \mathrm{~g} / \mathrm{dl}$, with a progressive decrease throughout the ICU stay. Overall, $44 \%$ of patients received at least one transfusion of red blood cells. Most transfusions were given in the first week, and thereafter at a rate of 1-2 units/week. Mean \pm SD time to first transfusion was $2.3 \pm 3.7$ days (median 1 day). Transfusion of red blood cells was associated with worsened patient outcomes. These data were similar to Western European ICU data collected in 1999, when hemoglobin at baseline, hemoglobin at the time of transfusion, and association between mortality and transfusion were evaluated (Vincent JL, Baron J-F, Reinhart K, et al. Anemia and blood transfusion in critically ill patients. JAMA 2002;288:1499-507). (Class II)

Rudis MI, Jacobi J, Hassan E, Dasta JF. Managing anemia in the critically ill patient. Pharmacotherapy 2004;24:229-47.

This literature review focuses on the use of transfusions for acute management of anemia in critically ill patients. The risks and benefits of red blood cell transfusion and the use of blood substitutes are reviewed. Despite measures to reduce blood wastage, many patients develop anemia of critical illness, characterized by low red blood cell production despite normal-to-high concentrations of erythropoietin, and in some cases inadequate erythropoietin production for the degree of anemia. Exogenous erythropoietin has raised red blood cell production and corrected anemia in a variety of patient populations. The authors make recommendations for therapy based on the limited data and expert opinion available.

Corwin HL, Gettinger A, Pearl RG, et al. 
Efficacy of recombinant human erythropoietin in critically ill patients. JAMA 2002;288:2827-35.

This randomized controlled trial compared erythropoietin $40,000 \mathrm{U} /$ week with placebo in a selected medical-surgical ICU population. Transfusion independence was the primary end point. The erythropoietin-treated patients were less likely than placebo patients to receive a red blood cell transfusion during the 28-day study, but their hemoglobin increase was greater than that of placebo patients. No significant adverse effects were reported. The regimen and end points were different from those used in an earlier pilot study (Corwin HL, Gettinger A, Rodriguez RM, et al. Efficacy of recombinant human erythropoietin in the critically ill patient. Crit Care Med 1999;27:2346-50). This trial, performed before another study (Hébert PC, Wells G, Blajchman MA, et al. A multicenter, randomized, controlled clinical trial of transfusion requirements in critical care. $\mathrm{N}$ Engl J Med 1999;340:409-17), compared restrictive versus liberal transfusion, resulted in a transfusion trigger higher than currently advocated. (Class I)

Taylor RW, Manganaro L, O'Brien J, et al. Impact of allogeneic packed red blood cell transfusion on nosocomial infection rates in the critically ill patient. Crit Care Med 2002;30: 2249-54.

The authors searched their clinical database for information regarding nosocomial infection in 1717 patients in their medical-surgical-trauma ICU for admissions from October 1998-August 2000. Risk of infection was calculated based on the entire cohort-patients receiving and not receiving red blood cell transfusion. The overall nosocomial infection rate was $5.94 \%$, and the rates were significantly different between the patients who received $(15.3 \%)$ and did not receive $(2.9 \%)$ transfusion $(\mathrm{p}<0.005)$. This difference persisted after adjusting for severity of illness with scores from the Mortality Prediction Model. In addition, an association was noted between the number of units administered and risk of infection. Transfused patients had longer ICU and hospital stays $(\mathrm{p}<0.0005)$. The risk of nosocomial infection, although not proven to be the direct result of red blood cell transfusion, may be the result of transfusion-related immunosuppression. Similar results have been documented in other populations, such as trauma patients (Claridge JA, Sawyer RG, Schulman AM, et al. Blood transfusions correlate with infections in trauma patients in a dose- dependent manner. Am Surg 2002;68:566-72). (Class II)

Goodnough LT, Brecher ME, Kanter MH, AuBuchon JP. Transfusion medicine. N Engl J Med 1999;340:438-47.

This article, the first of a two-part series, extensively reviews the risks of blood transfusion, such as human immunodeficiency virus, hepatitis B and C, and other hepatitis viruses. Other risks, such as hemolytic reactions, red cell bacterial contamination, transfusion-related lung injury, and immunomodulation are also reviewed. The indications for transfusion reflect the thinking at the time, although these have been altered by subsequent reports as described below.

Hébert PC, Wells G, Blajchman MA, et al. A multicenter, randomized, controlled clinical trial of transfusion requirements in critical care. N Engl J Med 1999;340:409-17.

These investigators randomized patients to either a liberal transfusion strategy designed to maintain a hemoglobin level of $10-12 \mathrm{~g} / \mathrm{dl}$ or a restrictive strategy designed to maintain a hemoglobin level of 7-9 g/dl. More red blood cell transfusions were given to the liberal group, and although the primary outcome of all-cause mortality was not different between the groups, the in-hospital mortality and multiple-organ dysfunction score were significantly higher in the liberal group. These data indicate that a transfusion threshold as low as $7 \mathrm{~g} / \mathrm{dl}$ was at least as effective and possibly superior to a more liberal transfusion strategy. A trend toward a lower survival was noted in a subset of patients with cardiovascular disease from the restrictive transfusion group. This led the authors to suggest that patients with unstable coronary ischemic syndromes may not benefit from a restrictive transfusion strategy (Hébert PC, Yetisir E, Martin C, et al. Is a low transfusion threshold safe in critically ill patients with cardiovascular disease? Crit Care Med 2001;29:227-34). (Class I)

\section{Infection}

\section{Bacterial}

Centers for Disease Control and Prevention and the Healthcare Infection Control Practices Advisory Committee. Guidelines for preventing health care-associated pneumonia, 2003 guidelines for the prevention of nosocomial pneumonia. MMWR Morb Mortal Wkly Rep 2004;53(RR-3):1-36. 
This report updates, expands, and replaces the previously published Guidelines for Prevention of Nosocomial Pneumonia. The new guidelines are designed to reduce the frequency of pneumonia and severe, acute lower respiratory tract infections in acute-care hospitals, other health care settings (e.g., ambulatory and long-term care institutions) and other facilities where health care is provided. The changes in the recommendations to prevent bacterial pneumoniaespecially ventilator-associated pneumonia-are directed at endotracheal intubation, water and environmental purification to avoid Legionella contamination, administration of palivizumab to prevent respiratory syncytial virus infection, use of newer antiviral agents for treatment of influenza, and identification of pertussis and lower respiratory tract infections caused by adenovirus and human parainfluenza viruses.

Chastre J, Wolff M, Fagon J-Y, et al. Comparison of 8 vs 15 days of antibiotic therapy for ventilator-associated pneumonia in adults. JAMA 2003;290:2588-98.

A prospective, randomized, double-blind, clinical trial in 401 patients with ventilatorassociated pneumonia conducted in 51 French ICUs found no difference in mortality or recurrent infection in patients treated with antibiotics for 8 days compared with those treated for 15 days. No differences were noted in resolution of fever, leukocyte count, the ratio of partial pressure of arterial oxygen to fraction of inspired oxygen, organ dysfunction, or radiologic scores between the two treatment groups. In a secondary analysis, there were more patients with nonfermenting gram-negative bacilli infections treated with 8 days of antibiotics who had pulmonary infection recurrence. These data demonstrated that for intensive care patients with ventilator-associated pneumonia, there is no clinical advantage in prolonging antimicrobial therapy to 15 days compared with 8 days. (Class I)

Chamot E, El Amari EB, Rohner P, Van Delden C. Effectiveness of combination antimicrobial therapy for Pseudomonas aeruginosa bacteremia. Antimicrob Agents Chemother 2003;47:2756-64.

This is a retrospective analysis of the empiric treatment of $P$. aeruginosa bacteremia in 115 episodes over 10 years, from 1988-1998. The work is unique in that 30-day mortality was an end point. Empiric therapy with combination antibiotics was associated with a better 30-day survival rate than empiric monotherapy. No difference was found in 30-day survival with monotherapy versus combination therapy if a definitive treatment was used after receipt of the culture and sensitivity report. These data support the long-held principle that $P$. aeruginosa bacteremia is better treated with a combination of antipseudomonal antibiotics than with monotherapy, at least until culture and susceptibility data have been received. (Class III)

Cosgrove SE, Sakoulas G, Perencevich E, Schwaber MJ, Karchmer AQ, Carmeli Y. Comparison of mortality associated with methicillin-resistant and methicillin-susceptible Staphylococcus aureus bacteremia: a metaanalysis. Clin Infect Dis 2003;36:53-9.

This meta-analysis reviewed mortality associated with both methicillin-susceptible $S$. aureus (MSSA) and methicillin-resistant S. aureus (MRSA) bacteremia in 31 studies that included 3963 patients; $65.7 \%$ had MSSA, 34.3\% MRSA. No significant difference in mortality was found in 24 studies; higher mortality associated with MRSA bacteremia was found in seven studies. When all data were combined, a significant increase in mortality associated with MRSA bacteremia was observed. This increased rate was also observed in a subgroup analysis in which adjustment was made for confounding variables.

Wunderink RG, Rello J, Cammarata SK, CroosDabrera V, Kollef MH. Linezolid vs vancomycin: analysis of two double-blind studies of patients with methicillin-resistant Staphylococcus aureus nosocomial pneumonia. Chest 2003;124:1789-97.

This is a post hoc analysis of two randomized, double-blind, multicenter studies of linezolid versus vancomycin for gram-positive nosocomial pneumonia. Data on 1019 patients were combined; 339 patients had documented S. aureus pneumonia, and 160 had documented MRSA pneumonia. Clinical cure rates for MRSA pneumonia were $50 \%$ for linezolid-treated patients and $35.5 \%$ for vancomycin-treated patients $(\mathrm{p}<0.01)$. The 28-day survival rate for patients with MRSA pneumonia was $80 \%$ with linezolid versus $63.5 \%$ with vancomycin $(\mathrm{p}=0.03)$. After adjusting for baseline variables, the difference favoring linezolid remained significant. Although this article is a retrospective analysis of combined data, it is the first to demonstrate a survival advantage for one appropriate antibiotic regimen over another in patients treated for MRSA pneumonia. (Class III) 
Neuhauser MM, Weinstein RA, Rydman R, Danziger LH, Karam G, Quinn JP. Antibiotic resistance among gram-negative bacilli in U.S. intensive care units. JAMA 2003;289:885-8.

Antibiotic susceptibility results for 35,790 nonduplicate gram-negative aerobic bacilli recovered from patients from 1994-2000 representing 43 states and the District of Columbia were reported. These results were compared with those from a similar analysis of data for 1990-1993. The activity of most antimicrobial agents decreased $6 \%$ or less over the study period. Ciprofloxacin activity decreased from $89 \%$ in $1990-1993$ to $86 \%$ in 1994 to $76 \%$ in 2000 . The decrease in activity of ciprofloxacin was associated significantly with the increased national use of fluoroquinolone therapy during the study period. Crossresistance to other broad-spectrum antibioticssuch as gentamicin, ceftazidime, imipenem, and amikacin-was observed in ciprofloxacinresistant isolates.

de Gans J, van de Beek D. Dexamethasone in adults with bacterial meningitis. N Engl J Med 2002;347:1549-56.

This prospective, randomized, double-blind, multicenter trial involved 301 adult patients with bacterial meningitis. Results demonstrated that dexamethasone $10 \mathrm{mg}$ administered just before or along with the first dose of antibiotic (intravenous amoxicillin) and then continued every 6 hours for 4 days was associated with a reduced risk of unfavorable outcome as indicated by the Glasgow Outcome Scale. Dexamethasone significantly affected unfavorable outcome in patients with pneumococcal meningitis but not meningitis due to Neisseria meningitides. The proportion of patients who died was significantly smaller in the dexamethasone group. Dexamethasone did not have a beneficial effect on neurologic sequelae, including hearing loss. Although management of meningitis differs throughout the world, these results support early treatment with dexamethasone in adults with bacterial meningitis. The direct applicability of these data in countries where vancomycin is the first-line therapy remains to be determined. (Class I)

Rello J, Paiva JA, Baraibar J, et al. International conference for the development of consensus on the diagnosis and treatment of ventilatorassociated pneumonia. Chest 2001;120:955-70.

This article presents consensus guidelines for diagnosis and treatment of ventilator-associated pneumonia. Twelve European intensivists were posed 21 questions regarding ventilatorassociated pneumonia. Answers were independently provided, and then were reported to and discussed among all participants. The guidelines cover several important topics, including initial empiric antibiotic therapy, monotherapy versus combination antibiotic therapy, combination therapy for P. aeruginosa infection, consideration of MRSA, duration of antibiotic therapy, and deescalation of antibiotic therapy for the management of ventilatorassociated pneumonia. Evidence for the recommendations is provided.

Raymond DP, Pellitier SJ, Crabtree TD, et al. Impact of rotating empiric antibiotic schedule on infectious mortality in an intensive care unit. Crit Care Med 2001;29:1101-8.

The authors present results from a prospective 2-year trial of protocol-driven antibiotic rotation in a surgical ICU. In year 1 , current practice was observed; in year 2, quarterly antibiotic rotation was adopted. Patients were stratified for rotation based on diagnosis of either pneumonia, or peritonitis or sepsis. A significant reduction in both gram-positive and gram-negative bacterial resistance occurred. A significant reduction in mortality associated with infection was identified during the rotation period. Length of ICU stay was not affected. (Class III)

Kollef MH, Sherman G, Ward S, Fraser VJ. Inadequate antimicrobial treatment of infections: a risk factor for hospital mortality among critically ill patients. Chest 1999;115:462-74.

This article demonstrates that critically ill patients who receive initial antimicrobial therapy for an infection that does not have activity against the causative pathogen(s) are significantly more likely to die. Using logistic regression analysis, the investigators found that inadequate antimicrobial treatment of infection was the most important independent predictor of mortality among the 2000-patient cohort. The data also show that up to $45.2 \%$ of intensive care patients with infection receive inadequate antimicrobial therapy. (Class II)

Hilf M, Yu VL, Sharp J, Zuravleff JJ, Korvick JA, Muder RR. Antibiotic therapy for Pseudomonas aeruginosa bacteremia: outcome correlations in a prospective study of 200 patients. Am J Med 1989;87:540-6. 
Pseudomonas aeruginosa bacteremia is associated with a high mortality rate. The aim of this prospective, observational report, which involved 200 patients, was to determine whether in vitro microbiology data translate into improved outcomes. Factors associated with increased mortality were a respiratory portal of entry, neutropenia, and use of monotherapy. Combination therapy, compared with monotherapy, demonstrated improved survival in patients with $P$. aeruginosa bacteremia $(\mathrm{p}<0.02)$. In vitro synergy testing data did not correlate with improved outcomes. (Class III)

\section{Fungal}

Pappas PG, Rex JH, Sobel JD, et al. Guidelines for the treatment of candidiasis. Clin Infect Dis 2004;38:161-89.

These guidelines are extensive and detailed evaluations of the treatment of Candida infections. The guidelines followed the U.S. Public Health Service grading system for rating recommendations in clinical guidelines. A detailed description of susceptibility testing methods for all antifungal agents and their interpretations is provided. Recommendations include updated dosing guidelines for amphotericin $\mathrm{B}$, amphotericin lipid-based formulations, and fluconazole. They also incorporate the use of voriconazole and caspofungin in the management of Candida infections. Specific recommendations regarding fungal prophylaxis are provided.

Mora-Duarte J, Betts R, Rotstein C, et al. Comparison of caspofungin and amphotericin $\mathrm{B}$ for invasive candidiasis. N Engl J Med 2002;347:2020-9.

In this randomized, double-blind, multicenter study of 239 patients with systemic or invasive candidiasis, caspofungin produced $73.4 \%$ success, compared with $61.7 \%$ for amphotericin $\mathrm{B}$, in an intent-to-treat analysis. In a predefined analysis of patients who met prespecified criteria for evaluation, $80.7 \%$ of caspofungin-treated patients and $64.0 \%$ of amphotericin-treated patients had successful outcomes $(p=0.03)$. Caspofungin showed consistently superior success among stratified subgroups. Drug-related adverse effects were significantly higher in the amphotericin B group. Failure due to toxic effects requiring change in therapy occurred significantly more frequently in the amphotericin group (16.5\%) compared with the caspofungin group $(2.8 \% ; \mathrm{p}=0.03)$. These data suggest that caspofungin is an effective yet less toxic alternative to amphotericin $\mathrm{B}$ for invasive candidiasis. (Class I)

Rex JH, Bennett JE, Sugar AM, et al. A randomized trial comparing fluconazole with amphotericin B for the treatment of candidemia in patients without neutropenia. N Engl J Med 1994;331:1325-30.

This multicenter, randomized, open-label trial involved 237 nonneutropenic patients with candidemia. Results demonstrated that fluconazole was equivalent to amphotericin B in overall clinical success and survival. Amphotericin B caused significantly greater elevations in serum blood urea nitrogen and creatinine levels, and more hypokalemia, than fluconazole. The mean \pm SD doses used in this study (amphotericin B $0.5 \pm 0.01 \mathrm{mg} / \mathrm{kg} /$ day, total dose $570 \pm 40 \mathrm{mg}$; fluconazole $5.3 \pm 0.2 \mathrm{mg} / \mathrm{kg} /$ day) are somewhat lower than recommended dosages. These data suggested that fluconazole could be considered for the management of candidemia, which was previously thought treatable only with amphotericin B. (Class I)

\section{Sepsis}

Dellinger RP, Carlet JM, Masur H, et al. Surviving sepsis campaign guidelines for management of severe sepsis and septic shock. Crit Care Med 2004:32:858-72.

These comprehensive guidelines were prepared by critical care and infectious disease experts from 11 international organizations. Recommendations were graded based on a modified Delphi methodology. The guidelines cover initial resuscitation, diagnosis, antibiotic therapy, source control, fluid therapy, vasopressors, inotropic therapy, steroids, drotrecogin alfa (activated), blood product administration, mechanical ventilation, glucose control, renal replacement therapy, bicarbonate therapy, deep vein thrombosis prophylaxis, stress ulcer prophylaxis, considerations for limitations of support, considerations for pediatric patients, and sedation, analgesia, and neuromuscular blockade. This article represents the culmination of years of research in sepsis, septic shock, and critical illness.

Annane D, Sebille V, Bollaert P-E, et al. Effect of treatment with low doses of hydrocortisone and fludrocortisone on mortality in patients with septic shock. JAMA 2002;288:862-71. 
This randomized, double-blind, placebocontrolled, parallel-group, multicenter trial involved 300 adults with septic shock. The investigators evaluated the effects of treatment with intravenous hydrocortisone $50 \mathrm{mg}$ every 6 hours and enteral fludrocortisone $50 \mu \mathrm{g}$ once/day for 7 days on 28-day mortality. Patients were stratified based on the results of a short corticotropin test. For nonresponders, mortality was $63 \%$ in the placebo group and $53 \%$ in the treatment group $(\mathrm{p}=0.04)$. For responders, as well as for all patients regardless of corticotropin test results, there was no significant effect of corticosteroids on survival. For nonresponders, the time to withdrawal of vasopressor support was 3 days shorter with corticosteroid therapy than placebo $(p=0.001)$. No differences in adverse events were noted between treatment groups. These data support corticotropin testing in patients with septic shock and the administration of replacement corticosteroids in patients with adrenal insufficiency. (Class I)

Rivers E, Nguyen B, Havstad S, et al. Early goaldirected therapy in the treatment of severe sepsis and septic shock. N Engl J Med 2001;345:1368-77.

This prospective, randomized trial involved 263 patients with severe sepsis or septic shock in an emergency department. Results showed a significant $16 \%$ absolute improvement in inhospital survival for patients receiving 6 hours of early goal-directed therapy compared with standard therapy before admission to the ICU. Early goal-directed therapy consisted of achieving a central venous pressure of 8-12 $\mathrm{mm}$ $\mathrm{Hg}$ or greater, mean arterial pressure of 65-90 $\mathrm{mm} \mathrm{Hg}$, and central venous oxygen saturation of $70 \%$ or greater. A protocol for achieving these goals was used. Urine output of $0.5 \mathrm{ml} / \mathrm{kg} /$ hour or greater was also a goal, but there was no specific therapy in the protocol directed toward urine output. Goals were achieved in $99.2 \%$ of the early therapy group, compared with $86.1 \%$ of the standard therapy group. The authors suggested that goal-directed therapy provided at the earliest stages of severe sepsis and septic shock has significant short- and long-term benefits. These results may affect the quality and timing of resuscitation before enrollment in future trials of sepsis and septic shock. (Class I)

Bernard GR, Vincent J-L, Laterre P-F, et al. Efficacy and safety of recombinant human activated protein $C$ for severe sepsis. N Engl J Med 2001;344:699-709.
This randomized, double-blind, placebocontrolled, multicenter trial involved 1690 patients with severe sepsis. The authors found that drotrecogin alfa (activated), which is recombinant human activated protein $C$, infused at $24 \mu \mathrm{g} / \mathrm{kg} /$ hour for 96 hours reduced all-cause 28 -day mortality from $30.8 \%$ to $24.7 \%$ ( $\mathrm{p}<0.005$ ). Reduced relative risk of death was $19.4 \%$. For patients at high risk of death, as predefined by Acute Physiology and Chronic Health Evaluation II score, drotrecogin alfa (activated) produced an absolute reduction in mortality of $13 \%$, from $44 \%$ to $31 \%$. The frequency of severe bleeding was higher in the treatment than placebo group (3.5\% vs $2.0 \%, \mathrm{p}=0.06$ ). Drotrecogin alfa (activated) was approved by the Food and Drug Administration for treatment of severe sepsis on the basis of this trial. (Class I)

\section{Neurosurgery and Neurology}

\section{Spinal Cord Injury}

American Association of Neurological Surgeons and Congress of Neurological Surgeons Joint Section on Disorders of the Spine and Peripheral Nerves. Blood pressure management after acute spinal cord injury: guidelines for the management of acute cervical spine and spinal cord injuries. Chapter 8. Neurosurgery 2002;50(3 suppl):S58-62.

The authors state evidence is insufficient to support treatment standards or guidelines for blood pressure management for patients with acute spinal cord injury. They do, however, recommend avoiding hypotension (systolic blood pressure $<90 \mathrm{~mm} \mathrm{Hg}$ ) and maintaining mean arterial pressure at $85-90 \mathrm{~mm} \mathrm{Hg}$ for 7 days after injury to improve spinal cord perfusion.

American Association of Neurological Surgeons and Congress of Neurological Surgeons Joint Section on Disorders of the Spine and Peripheral Nerves. Pharmacological therapy after acute cervical spinal cord injury: guidelines for the management of acute cervical spine and spinal cord injuries. Chapter 9. Neurosurgery 2002;50(3 suppl):S63-72.

This is one of the most controversial chapters in the guidelines, and the authors recommend that readers review the data and comments to formulate their own opinions regarding treatment options. They state that there is insufficient evidence for treatment standards or guidelines for using corticosteroid therapy. The group recom- 
mends that methylprednisolone administered for 24-48 hours can be considered a treatment option for patients with acute spinal cord injury; however, the authors first acknowledge that the evidence suggesting harmful side effects is more consistent than evidence supporting clinical benefit.

American Association of Neurological Surgeons and Congress of Neurological Surgeons Joint Section on Disorders of the Spine and Peripheral Nerves. Deep venous thrombosis and thromboembolism in patients with cervical spinal cord injuries: guidelines for the management of acute cervical spine and spinal cord injuries. Chapter 10. Neurosurgery 2002;50(3 suppl): S73-80.

In this chapter, prophylaxis of deep vein thrombosis is recommended as a standard of care for patients with acute spinal cord injury. The authors support the use of low-molecular-weight heparins, rotating beds, adjusted-dose heparin, or a combination of these modalities, as well as lowdose heparin in combination with pneumatic compression stockings or electrical stimulation as treatment strategies for prophylaxis. The guidelines state that low-dose heparin therapy alone and oral anticoagulation alone are not recommended. Other suggestions include the administration of various diagnostic tests, 3 months of prophylactic treatment, and vena cava filters for patients not responding to anticoagulation or who have contraindications to anticoagulation and/or mechanical devices.

Hurlbert RJ. Methylprednisolone for the acute cord injury: an inappropriate standard of care. J Neurosurg Spine 2000:93:1-7.

This article provides a critical evaluation of the results and conclusions of the National Acute Spinal Cord Injury Studies (NASCIS) II and III to determine the influence they should have on practice standards for patients with acute spinal cord injury. The author converted the published data from these trials into the original raw data to further evaluate the effects on outcome. He concluded that although these studies were well designed and well conducted, evidence to support the use of methylprednisolone therapy for patients with acute spinal cord injury is weak and clinically irrelevant. He suggested that administration of methylprednisolone should be considered experimental, and the 48-hour treatment regimen should not be recommended.
Bracken MB, Shepard MJ, Holford TR, et al. Administration of methylprednisolone for 24 or 48 hours or tirilazad mesylate for 48 hours in the treatment of acute spinal cord injury: results of the third national acute spinal cord injury randomized controlled study. JAMA 1997;277:1597-604.

The NASCIS III was a double-blind, randomized, controlled trial involving 499 patients with acute spinal cord injury. At 6-week and 6-month follow-up, a significant neurologic recovery persisted with the 48-hour methylprednisolone regimen that had been started within 3-8 hours after injury compared with the 24-hour regimen (neurologic change scores at 6 weeks, 7.6 vs $12.5, p=0.04$; at 6 months, 11.2 vs $17.6, \mathrm{p}=0.01$ ). No difference in recovery was found when treatment was started within 3 hours of injury. In a third study group, tirilazad demonstrated efficacy similar to that of the 24-hour methylprednisolone regimen and was well tolerated. The authors concluded that methylprednisolone therapy should be continued for 24 hours if started within 3 hours of injury, but continued for 48 hours if started 3-8 hours after injury. (Class I)

Bracken MB, Shepard MJ, Collins WF, et al. A randomized, controlled trial of methylprednisolone or naloxone in the treatment of acute spinal-cord injury: results of the second national acute spinal cord injury study. N Engl J Med 1990;322:1405-11.

In the NASCIS I trial, methylprednisolone in dosages up to $1000 \mathrm{mg} /$ day did not improve neurologic recovery (sensory or motor function) in 330 patients with acute spinal cord injury. This article describes NASCIS II, a double-blind, placebo-controlled trial involving 487 patients treated within 8 hours of injury. Treatment consisted of a high-dose methylprednisolone intravenous bolus of $30 \mathrm{mg} / \mathrm{kg}$ followed by continuous infusion of $5.4 \mathrm{mg} / \mathrm{kg} /$ hour for 23 hours. Significant motor function and sensation were maintained at 6 weeks and 6 months with methylprednisolone compared with placebo or a naloxone bolus of $5.4 \mathrm{mg} / \mathrm{kg}$ followed by infusion of $4 \mathrm{mg} / \mathrm{kg} /$ hour for 23 hours. Complication rates were similar among the three groups. (Class I)

Head Injury

CRASH Trial Collaborators. Effect of intravenous corticosteroids on death within 14 days of 10008 
adults with clinically significant head injury (MRC CRASH trial): randomized placebocontrolled trial. Lancet 2004;364:1321-8.

The Medical Research Council's Corticosteroid Randomization After Significant Head Injury (MRC CRASH) trial was a multicenter, randomized, placebo-controlled trial involving 10,008 adults with severe head injury. The goal was to determine the effect of early administration of methylprednisolone on risk of death at 2 weeks or disability at 6 months. Patients were randomized to receive intravenous methylprednisolone $2 \mathrm{~g}$ followed by $0.4 \mathrm{~g}$ /hour for 48 hours, or placebo, within 8 hours of injury. The study was stopped prematurely because an interim analysis showed a significant increase in relative risk of all-cause death in the methylprednisolone-treated group (RR 1.18, 95\% CI 1.09-1.27, p=0.0001). The relative increase in mortality in the methylprednisolone group did not differ by the severity or time of injury. The exact mechanism for the increased mortality is unknown. This is the first study that clearly refutes the mortality benefit of corticosteroids in the treatment of patients with severe head injury. (Class I)

Bullock RM, Chesnut RM, Clifton GL, et al. Use of mannitol. J Neurotrauma 2000;17:521-5.

Mannitol is an osmotic diuretic used to control raised intracranial pressure in patients with severe head injury. This is a task force-based guideline for treatment of traumatic intracranial hypertension with mannitol. The authors suggest that a bolus dose may be more effective than a continuous infusion. In addition, they advocate keeping serum osmolality below 320 $\mathrm{mOsm} / \mathrm{kg}$ and avoiding hypovolemia to minimize the risk of acute tubular necrosis.

Bullock RM, Chesnut RM, Clifton GL, et al. Use of barbiturates in the control of intracranial hypertension. J Neurotrauma 2000;17:527-30.

In patients with severe head injury, uncontrolled intracranial hypertension is associated with a high risk of mortality (84-100\%). This article consists of guidelines for the use of barbiturates in treating such patients. In hemodynamically stable patients, high-dose barbiturates may be administered to lower intracranial pressure refractory to conventional medical or surgical treatment. Efficacy has not been proven for prophylactic lowering of intracranial pressure. These guidelines were based on a task force review.

Bullock RM, Chesnut RM, Clifton GL, et al. Role of steroids. J Neurotrauma 2000;17:531-5.
Steroids have been investigated as a means to control raised intracranial pressure in patients with head trauma. This task force review did not support steroid administration because most of the available evidence does not suggest improved outcomes or lowered intracranial pressure.

Bullock RM, Chesnut RM, Clifton GL, et al. Role of antiseizure prophylaxis following head injury. J Neurotrauma 2000;17:549-53.

These guidelines were based on a task force review of the literature on anticonvulsants for posttraumatic seizure prophylaxis. The authors concluded that phenytoin and carbamazepine decreased the risk of early posttraumatic seizure (defined as seizure onset within 7 days of injury). Improved survival benefit was not proven. The authors suggested valproic acid as an alternative agent, although it has been associated with a slightly higher mortality.

Haltiner AM, Newell DW, Temkin NR, Dikmen SS, Winn HR. Side effects and mortality associated with the use of phenytoin for early posttraumatic seizure prophylaxis. J Neurosurg 1999;91:588-92.

According to a secondary analysis of a prospective, randomized, double-blind, placebocontrolled trial, improved survival was not associated with the reduction of early posttraumatic seizures (within 7 days of injury) in 404 patients receiving phenytoin. Hypersensitivity reactions to phenytoin, primarily an idiosyncratic maculopapular rash, increased from $0.6 \%$ during week 1 to $2.5 \%$ during week 2 . Overall, short-term phenytoin therapy was well tolerated. The authors suggest that mortality in patients who developed posttraumatic seizures might be linked to increased severity of the original traumatic brain injury. (Class II)

Temkin NR, Dikmen SS, Anderson GD, et al. Valproate therapy for prevention of posttraumatic seizures: a randomized trial. J Neurosurg 1999;91:593-600.

Seizures are common in patients with recent traumatic brain injury. This randomized, controlled trial compared a 7 -day course of phenytoin (132 patients) with a l-month (120 patients) and 6-month (127 patients) course of valproate for prevention of seizures associated with head trauma. Differences in the frequencies of seizures, mortality, and adverse effects were not statistically significant between groups. A trend toward higher mortality was found in the valproate group; however, none of the deaths 
were attributable to the most common adverse effects reported-liver dysfunction and thrombocytopenia. The authors concluded that valproate should not be routinely used for prophylaxis of posttraumatic seizures. (Class I)

Temkin NR, Dikmen SS, Wilensky AJ, Keihm J, Chabal S, Winn HR. A randomized, double-blind study of phenytoin for the prevention of posttraumatic seizures. N Engl J Med 1990;323: 497-502.

This randomized, double-blind, placebocontrolled study is the landmark article supporting short-course phenytoin therapy for seizure prophylaxis in patients with severe head injury. Phenytoin $(20-\mathrm{mg} / \mathrm{kg}$ load) or placebo was administered within 24 hours of injury, and maintenance doses were continued for 12 months. Phenytoin doses were adjusted to maintain free phenytoin levels within a target range of $0.75-1.5 \mathrm{mg} / \mathrm{L}$. Patients were followed for 24 months. One week after injury, the seizure rate was $3.6 \%$ and $14.2 \%$ in the phenytoin and placebo groups, respectively $(\mathrm{p}<0.001)$. The differences in the frequency of late-onset seizures (day 8-year 2) between groups was not statistically significant $(p>0.2)$. The authors concluded that phenytoin is effective only for prevention of early-onset ( $<7$ days) seizures after severe head injury. (Class I)

\section{Hemorrhagic Stroke}

Fewel ME, Park P. The emerging role of recombinant-activated factor VII in neurocritical care. Neurocrit Care 2004;1:19-30.

Factor VII is beginning to play a role in the area of neurocritical care. A review of the pharmacology, pharmacokinetics, and treatment strategies in the critically ill neurosurgical patient population is discussed. The authors also review recently published case studies. This article provides a nice overview of factor VII treatment options in neurocritical care.

Sen J, Belli A, Albon H, Morgan L, Ptezold A, Kitchen N. Triple-H therapy in the management of aneurysmal subarachnoid haemorrhage. Lancet Neurol 2003;2:614-21.

Vasospasm, a major complication after subarachnoid hemorrhage, is associated with high morbidity and mortality. Hypervolemia, hypertension, and hemodilution (triple- $\mathrm{H}$ ) therapy is accepted as a standard of care; however, no randomized, controlled trials have been conducted to prove efficacy in the treatment of vasospasm. The authors review the literature and discuss the rationale for triple-H therapy.

Broderick JP, Adams HP, Barsan W, et al. Guidelines for the management of spontaneous intracerebral hemorrhage: a statement for healthcare professionals from a special writing group of the stroke council of the American Heart Association. Stroke 1999;30:905-15.

A task force was formed to develop practice guidelines for the management of intracerebral hemorrhage. These guidelines provide recommendations for diagnosis, acute treatment, medical management, surgical treatment, and prevention of intracerebral hemorrhage. Algorithms for the management of blood pressure and intracranial pressure, parameters for fluid management, and recommendations for seizure prophylaxis and temperature regulation are provided.

\section{Ischemic Stroke}

Adams HP, Adams RJ, Brott T, et al. Guidelines for the early management of patients with ischemic stroke: a statement from the stroke council of the American Stroke Association. Stroke 2003;34:1056-83.

These guidelines, which update the original 1994 guidelines, are intended to guide clinicians in the diagnosis and management of patients during the first 24-48 hours after ischemic stroke. Recommendations are provided for diagnostic testing and examination, general supportive care and treatment of complications, use of thrombolysis, role of anticoagulation, surgical interventions, and management of neurologic complications. Each recommendation is graded based on the level of supporting evidence.

Albers GW, Bates VE, Clark WM, Bell R, Verro $P$, Hamilton SA. Intravenous tissue-type plasminogen activator for treatment of acute stroke: the standard treatment with alteplase to reverse stroke (STARS) study. JAMA 2000;283: 1145-50.

The aim of this trial was to report the clinical outcomes and adverse effects of tissue-type plasminogen activator when used in practice. The 30-day clinical outcomes of intravenous tissue-type plasminogen activator $0.9 \mathrm{mg} / \mathrm{kg}$, maximum $90 \mathrm{mg}$, were investigated in 389 consecutive patients with acute ischemic stroke. The 30-day mortality was 13\%; in addition, 35\% of patients had a very favorable outcome and 
$43 \%$ were functionally independent (modified Rankin scores of $\leq 1$ and $\leq 2$, respectively). Safety data from this observational study were consistent with the low frequency of symptomatic intracranial hemorrhage found in the National Institute of Neurological Disorders and Stroke trial. Caution should still be exercised for patients with major early infarction. (Class II)

Clark WM, Wissman S, Albers GW, Jhamandas JH, Madden KP, Hamilton S. Recombinant tissue-type plasminogen activator (alteplase) for ischemic stroke 3 to 5 hours after symptom onset: the ATLANTIS study: a randomized controlled trial. JAMA 1999;282:2019-26.

Recombinant tissue-type plasminogen activator originally was studied when administered within 3 hours of symptom onset in patients with acute ischemic stoke. However, only a few patients received the drug within this time frame. In this randomized, placebo-controlled trial, alteplase was initiated in 3-5 hours after symptom onset. Outcomes were neurologic recovery at 90 days, functional outcome measures at 30 and 90 days, and serious adverse events. Neurologic recovery, functional recovery, and mortality were similar in both groups. Asymptomatic, symptomatic, and fatal intracranial hemorrhages were significantly higher in the alteplase group $(p<0.05)$. The authors concluded that there was no benefit to administering alteplase 3-5 hours after symptom onset. (Class I)

Hacke W, Kaste M, Fieschi C, et al. Randomised double-blind placebo-controlled trial of thrombolytic therapy with intravenous alteplase in acute ischaemic stroke (ECASS II). Lancet 1998;352:1245-51.

The primary objective of this multicenter trial was to determine whether alteplase $0.9 \mathrm{mg} / \mathrm{kg}$ given within 6 hours of symptom onset would improve overall function in 800 patients with acute ischemic stroke. Efficacy of alteplase was independent of administration time (no difference when given $<3$ or 3-6 hrs after stroke). No significant difference in efficacy or mortality was observed between alteplase and placebo at the 30- and 90-day end points. As seen in the first European Cooperative Acute Stroke Study (ECASS I) and the National Institute of Neurological Disorders and Stroke (NINDS) trial, symptomatic intracranial hemorrhage was higher in the alteplase group $(8.8 \%)$ than in the placebo group (3.4\%). (Class I)
NINDS t-PA Stroke Study Group. Intracerebral hemorrhage after intravenous t-PA therapy for ischemic stroke. Stroke 1997;28:2109-18.

Administration of tissue plasminogen activator (t-PA) has been associated with increased risk of intracranial hemorrhage when used to treat ischemic stroke. The authors investigated whether any variables collected in the NINDS t-PA stroke trial were associated with intracranial hemorrhage. Severity of neurologic deficit (OR $1.8,95 \%$ CI 1.2-2.9) and brain edema and mass effect by computed tomography (OR 7.8, 95\% CI 2.2-27.1) were the only independent variables associated with intracranial hemorrhage. Patients with severe neurologic deficits had more favorable outcomes at 90 days in the treatment group than in the placebo group (OR 4.3, 95\% CI 1.6-11.9). The authors concluded that these patients were still candidates for t-PA if the agent was administered within 3 hours of symptom onset. (Class II)

National Institute of Neurological Disorders and Stroke rt-PA Stroke Study Group. Tissue plasminogen activator for acute ischemic stroke. N Engl J Med 1995;333:1581-7.

Previous trials have suggested that early intervention with thrombolytic therapy improves clinical outcomes in patients with acute ischemic stroke, although the therapy is associated with a risk of symptomatic intracranial hemorrhage. In this prospective, randomized, double-blind, placebo-controlled trial, 624 patients were treated with recombinant tissue plasminogen activator (rt-PA) $0.9 \mathrm{mg} / \mathrm{kg}$, maximum $90 \mathrm{mg}$. The results demonstrated significantly decreased neurologic deficit at 3 and 12 months in patients treated within 3 hours of stroke onset (OR 1.7, 95\% CI 2-2.6). Symptomatic intracranial hemorrhage occurred more frequently in the rt-PA group (6.4\%) than in the placebo group $(0.6 \%)$ during the first 36 hours $(\mathrm{p}<0.001)$. No difference in mortality was detected. (Class I)

Hacke W, Kaste M, Fieschi C, et al. Intravenous thrombolysis with recombinant tissue plasminogen activator for acute hemispheric stroke: the European cooperative acute stroke study (ECASS). JAMA 1995;274:1017-25.

Restoration of cerebral blood flow is the goal of thrombolytic therapy in stroke patients. This randomized, controlled trial compared rt-PA with placebo in 620 patients with acute ischemic stroke. The patients presented within 6 hours of symptom onset and had experienced a stable 
(moderate-to-severe) stroke without signs of infarction on computed tomography. No difference in the primary outcome of functional scores at 90 days was found with the intent-totreat analysis. The target population analysis revealed that one of the functional scores (Rankin score) was in favor of rt-PA $(\mathrm{p}<0.05)$. Mortality was similar between the two groups, but parenchymal hemorrhages and mortality occurred significantly more often in the rt-PA group. The authors concluded that rt-PA was effective, and that the risk of bleeding and death does not outweigh the positive effects of t-PA. They recommended more stringent criteria for patient selection to reduce adverse effects. (Class I)

\section{Seizures}

Lowenstein DH. Treatment options for status epilepticus. Curr Opin Pharmacol 2003;3:6-11.

Progress in technology and diagnostic tools have enhanced our understanding and appreciation of the complexities of status epilepticus. This review article addresses the treatment of status epilepticus, focusing on pharmacology and providing both clinical and pharmacologic rationales for therapy. The author advocates individualized algorithms based on patient response to treatment and discusses treatment options not available at the time of a 1998 review (Lowenstein DH, Alldredge BK. Current concepts: status epilepticus. N Engl J Med 1998;338:970-6). The author concluded that more aggressive therapies are likely to be required if patients do not respond to first-line drugs. However, large-scale clinical trials to determine the safety and efficacy of new, more potent agents are still lacking.

Claasen J, Hirsch LJ, Emerson RG, Mayer SA. Treatment of refractory status epilepticus with pentobarbital, propofol, or midazolam: a systematic review. Epilepsia 2002;43:146-53.

The absence of controlled, prospective studies comparing available treatment options for refractory status epilepticus makes it difficult to compare the relative efficacy and safety of these options. This article provides a systematic review of peer-reviewed publications reporting the treatment of adults with status epilepticus refractory to at least two standard anticonvulsants. Outcome measures evaluated were the frequency of short-term treatment failure (within 1-6 hrs), mortality, and drug titration goals. Twenty-eight publications describing 193 patients receiving pentobarbital, propofol, or midazolam were included in the analysis. Of the 193 patients, 48\% died, with no differences based on the treatment received. Although pentobarbital was usually titrated to electroencephalogram background suppression, propofol and midazolam were titrated to the dosage needed to achieve seizure suppression. Overall, the limited data reviewed in this article suggest that treatment with pentobarbital or titration of any agent to electroencephalogram background suppression may be the most effective strategy for managing refractory status epilepticus. However, there was no obvious improvement in mortality. Prospective, controlled evaluations of this issue are needed.

Lowenstein DH, Alldredge BK. Current concepts: status epilepticus. N Engl J Med 1998;338:970-6.

This article provides a concise and clinically useful review of the clinical presentation, pathophysiology, initial management, and pharmacologic treatment of status epilepticus. The review contains a treatment algorithm that is widely employed in the management of patients with status epilepticus.

Treiman DM, Meyers PD, Walton NY, et al. A comparison of four treatments for generalized convulsive status epilepticus. N Engl J Med 1998;339:792-8.

In this multicenter, randomized, double-blind trial, four intravenous regimens were compared for in-hospital treatment of generalized convulsive status epilepticus. A total of 570 patients were randomized to receive diazepam $0.15 \mathrm{mg} / \mathrm{kg}$ followed by phenytoin $18 \mathrm{mg} / \mathrm{kg}$, lorazepam $0.1 \mathrm{mg} / \mathrm{kg}$, phenobarbital $15 \mathrm{mg} / \mathrm{kg}$, or phenytoin $18 \mathrm{mg} / \mathrm{kg}$. Treatment success was defined as the absence of motor and electrical activity within 20 minutes of drug infusion, with no evidence of recurrence over the next 40 minutes. Intent-to-treat analysis revealed no statistically significant differences among regimens. For 384 patients with overt generalized convulsive seizures, lorazepam was more effective than phenytoin $(\mathrm{p}=0.02)$ but did not differ from the diazepam-phenytoin and phenobarbital regimens. Based on at least comparable safety and efficacy for the four regimens, the authors concluded that for patients with generalized convulsive status epilepticus, lorazepam should be the initial treatment due to its ease of administration and improved response compared with phenytoin. (Class I) 


\section{Nutrition}

Jacobs DG, Jacobs DO, Kudsk KA, et al. Practice management guidelines for nutritional support of the trauma patient. J Trauma 2004;57:660-79.

This guideline was developed by a work group of EAST. Each of the six guideline subsections (route, timing, site, macronutrients, monitoring, and type of nutritional support) is a freestanding, evidence-based document. References and evidence tables associated with the guideline can be obtained on the EAST Web site (http://www. east.org). The guideline contains an algorithm summarizing the nutritional management of trauma patients.

Barr J, Hecht M, Flavin KE, et al. Outcomes in critically ill patients before and after the implementation of an evidence-based nutritional management protocol. Chest 2004;125:1446-57.

The primary end point of this before-and-after, prospective investigation (100 patients in each phase) was to evaluate the impact of a nutritional management protocol on the time to initiation of feeding of patients in two medical-surgical ICUs. The protocol was evidence based but lacked high-level evidence for some recommendations. Enteral versus parenteral nutrition, ability to reach caloric goals, and length of ICU stay were evaluated. Patients in the postimplementation group were more likely than those in the preimplementation group to be fed enterally, and their mean duration of mechanical ventilation was decreased. However, the results were statistically significant $(\mathrm{p}=0.009$ and $\mathrm{p}=0.03$, respectively) only after adjusting for a variety of covariates, such as baseline nutritional status and severity of illness. The logic behind this adjustment was questioned in an editorial accompanying the article (Zaloga GP, Bortenschlager L. Anorexia protocolis. Chest 2004;125:1195-7). No other significant differences between groups were noted, probably because of the comparable number of patients receiving enteral feeds in the preprotocol and postprotocol groups (68\% and $78 \%$, respectively, $\mathrm{p}=0.08$ ). This study is notable because of its prospective design and comprehensive approach to the nutritional management of critically ill patients. (Class II)

American Society of Parenteral and Enteral Nutrition Board of Directors and the Clinical Guidelines Task Force. Guidelines for the use of parenteral and enteral nutrition in adult and pediatric patients. J Parenter Enteral Nutr 2002;26(suppl):1SA-96.
Based on an extensive review of the literature, an interdisciplinary, technical advisory group of nutrition support specialists updated the 1993 guidelines to assist clinicians in managing patients in both outpatient and inpatient settings. Each topic is presented in the same format: background, evidence, special considerations (if applicable), and graded recommendations for specialized nutrition support.

Heyland DK, Novak F, Drover JW, Jain M, Su X, Suchner U. Should immunonutrition become routine in critically ill patients? JAMA 2001;286:944-53.

The appropriate indications for the use of enteral feeding formulas supplemented with immune-altering nutrients in the ICU are controversial despite the availability of consensus guidelines (Kudsk KA, Moore F, Martindale RG, Cresci G, McClave S, Schloerb PR. Consensus recommendations from the U.S. summit on immune-enhancing enteral therapy. J Parenter Enteral Nutr 2001;25(suppl):S61-2). This metaanalysis is important not only because it evaluates the use of such formulas in critically ill patients, but also because it raises important questions and concerns regarding research in this area.

Heyland DK, MacDonald S, Keefe L, Drover JW. Total parenteral nutrition in the critically ill patient: a meta-analysis. JAMA 1998;280:2013-19.

This meta-analysis of 26 randomized trials evaluated morbidity and mortality outcomes in 2211 surgical or critically ill patients receiving total parenteral nutrition (TPN). Although TPN did not improve mortality, a trend toward decreased complication rates was found in patients classified as malnourished.

Veterans Affairs Total Parenteral Nutrition Cooperative Study Group. Perioperative total parenteral nutrition in surgical patients. N Engl J Med 1991;325:525-32.

Outcome data for morbidity and mortality in surgical patients requiring TPN are lacking in the published literature. The primary objective of this prospective, randomized, controlled trial was to determine whether perioperative TPN decreased serious complications secondary to major abdominal or thoracic surgery. A total of 395 patients were randomized-192 to the TPN group and 203 to the control group. Rates of major complications, mortality, and noninfectious complications were not statistically significant between the two groups. Patients receiving TPN had more infectious complications 
than controls ( $14.1 \%$ vs $6.4 \%$, RR $2.20,95 \%$ CI 1.19-4.05). Severely malnourished patients, however, experienced an overall benefit from TPN since a significantly lower rate of infectious complications was found in this group (RR 0.12, 95\% CI 0.02-0.91). (Class I)

Sedation, Analgesia, Delirium, and

Neuromuscular Blockade

Baumann MH, McAlpin W, Brown K, et al. A prospective randomized comparison of train-offour monitoring and clinical assessment during continuous ICU cisatracurium paralysis. Chest 2004;126:1267-73.

These authors tested the recommendation from the guidelines of the Society of Critical Care Medicine and the American Society of HealthSystem Pharmacists for routine use of a peripheral nerve stimulator with continuous neuromuscular blockade. Medical intensive care patients were randomized to train-of-four every 4 hours versus clinical assessment during cisatracurium infusions of 50-70 hours. Cisatracurium was titrated to maintain one or two of four twitches. No difference was demonstrated in time to recovery of neuromuscular function (four of four twitches) or dosing requirement for the 30 patients studied. The authors suggested that routine use of train-offour was not needed during cisatracurium infusion. The article and its accompanying editorial (Sessler CN. Train-of-four to monitor neuromuscular blockade? Chest 2004;126: 1018-22) correctly suggest that these data cannot be extrapolated to infusions of aminosteroidal neuromuscular blockade agents, whereas accumulation of active metabolites may contribute to prolonged drug effects. (Class I)

Vasile B, Rasulo F, Candiani A, Latronico N. The pathophysiology of propofol infusion syndrome: a simple name for a complex syndrome. Intensive Care Med 2003;29:1417-25.

The authors developed a hypothesis for the development of a syndrome characterized by cardiac failure, rhabdomyolysis, severe metabolic acidosis, and renal failure after prolonged or high-dose propofol infusion. This syndrome appears to be rare; only 21 pediatric and 14 adult cases have been reported in the literature. Most of the reports involve patients with neurologic illnesses or acute inflammatory diseases (e.g., severe sepsis) as priming factors in combination with triggering factors, such as concurrent catecholamine infusions or steroids. Propofol doses greater than $5 \mathrm{mg} / \mathrm{kg} /$ hour for more than 48 hours were reported in the cases described.

Ely EW, Truman B, Shintani A, et al. Monitoring sedation status over time in ICU patients: reliability and validity of the Richmond agitationsedation scale (RASS). JAMA 2003;289:2983-91.

The RASS is a modification of the Riker Sedation-Agitation Scale, expanded to score 10 levels rather than the original seven. In particular, the degrees of light sedation are expanded to differentiate response to voice from response to physical stimulation. This prospective cohort trial evaluated the RASS used in adult patients in medical and coronary ICUs compared with the Glasgow Coma Scale and Ramsay scale. The study serves as an independent validation of the utility of the RASS. In 290 paired observations by nurses, the RASS and Ramsay scale both demonstrated excellent interrater reliability as well as criterion, construct, and face validity. Both were superior to the Glasgow Coma Scale. The RASS detected changes in sedation status over consecutive days in patients with varying levels of consciousness and delirium. Scores changed appropriately with dosages of sedatives and analgesics. (Class II)

Odhner M, Wegman D, Freeland N, et al. Assessing pain control in nonverbal critically ill adults. Dimens Crit Care Nurs 2003;22:260-7.

This is the second observational pain scale to be published and validated at the site of origin. The nonverbal pain scale yields a score of $0-2$ for each of the major categories (facial expression, activity [movement], guarding, vital signs, and skin appearance), for a potential score of 0-10. Validation occurred with 100 paired assessments on all three 8-hour nursing shifts, although most tests were performed during the day. The nonverbal pain scale was compared with a pediatric scale for face, legs, activity, cry, and consolability due to the lack of a previous gold standard for assessment of nonverbal patients. Interrater reliability for the nonverbal pain scale was good $(\alpha=0.78)$. However, no assessment was performed to ensure that the change on the nonverbal pain scale was correlated with different degrees of pain. (Class II)

Nasraway SA, Jacobi J, Murray MJ, Lumb PA. Sedation, analgesia, and neuromuscular blockade of the critically ill adult: revised clinical practice guidelines for 2002. Crit Care Med 2002;30; 117-18. 
This introductory document accompanies two corresponding guideline documents (described below) developed jointly by the American Society of Health-System Pharmacists and the Society of Critical Care Medicine. Levels of evidence and definitions for the grades of recommendation are described in this document. The three articles in this series have also been published elsewhere (Am J Health-Syst Pharm 2002;59:147-95).

Jacobi J, Fraser GL, Coursin DB, et al. Clinical practice guidelines for the sustained use of sedatives and analgesics in the critically ill adult. Crit Care Med 2002;30:119-41.

This guideline, second in the series of three articles, summarizes the extensive literature on analgesia and sedation of critically ill patients with emphasis on patient assessment, therapeutic options, and recommendations for optimal therapy. Examples of assessment tools are provided along with an algorithm approach to treatment plan development. Associated topics include management of delirium and issues related to nonpharmacologic therapy and sleep.

Murray MJ, Cowen J, DeBlock H, et al. Clinical practice guidelines for sustained neuromuscular blockade in the adult critically ill patient. Crit Care Med 2002;30:142-56.

The third article in this series similarly summarizes the literature on the use of neuromuscular blocking agents in critical care patients. The authors describe the mechanism of action and the pharmacology of the individual agents. They also describe the appropriate indications and recommended agents, along with suggestions for how to monitor for effectiveness and adverse effects. The article also reviews the syndromes and risk factors leading to delayed muscle recovery after treatment with these agents. A template for evaluation of the pharmacoeconomic impact of individual agents is provided.

Barr J, Zomorodi K, Bertaccini EJ, et al. A double-blind, randomized comparison of IV lorazepam versus midazolam for sedation of ICU patients via a pharmacologic model. Anesthesiology 2001;95:286-98.

In this double-blind clinical trial, 24 mechanically ventilated patients were randomized after surgery to receive sedation with lorazepam or midazolam by continuous infusion for 12-72 hours. Sedation was titrated through infusion rate changes with a goal of Ramsay scale level
3-4. Serum concentrations and pharmacodynamic effects were also measured. The estimated sedative potency of lorazepam was twice that of midazolam on a milligram-tomilligram basis. The relative amnesic potency of lorazepam was 4 compared with midazolam. Lorazepam was associated with longer times to emergence from 72 hours of sedation with both deep (31.1 hrs) and light (11.9 hrs) regimens compared with deep and light regimens of midazolam (14.9 and 3.9 hrs, respectively). However, excluding patients with renal or hepatic insufficiency may have minimized accumulation of midazolam's active metabolites that could alter awakening times. (Class I)

Garnacho-Montero J, Madrazo-Osuna J, GarciaGarmendia JL, et al. Critical illness polyneuropathy: risk factors and clinical consequences. A cohort study in septic patients. Intensive Care Med 2001;27:1288-96.

Intensive care patients can experience prolonged weakness after a critical illness such as sepsis. Myopathy treated with corticosteroids has been well described, and the potential contribution of neuromuscular blocking agents was well documented in the neuromuscular blocking agent guidelines. In this article, the authors studied 73 patients with sepsis and assessed neuromuscular changes with electrophysiologic studies on the days 10 and 21 of mechanical ventilation. Multivariate logistic regression analysis of the risk factors for critical-illness polyneuropathy demonstrated that hyperosmolality, parenteral nutrition, neuromuscular blocking agents, and neurologic failure were independently associated with critical-illness polyneuropathy, whereas renal replacement therapy appeared protective. Forty six patients had critical-illness polyneuropathy on the first assessment, with an additional four diagnosed at the second evaluation. As demonstrated by others, critical-illness polyneuropathy contributed to a longer duration of mechanical ventilation and hospital stay. (Class II)

Kress JP, Pohlman AS, O'Connor MF, Hall JB. Daily interruption of sedative infusions in critically ill patients undergoing mechanical ventilation. N Engl J Med 2000;342:1471-7.

In this study, 128 critically ill, mechanically ventilated patients were randomized to daily interruption of sedative infusion or routine sedative titration. Patients were further randomized to therapy with propofol or midazolam. 
Duration of mechanical ventilation was reduced from 7.3 to 4.9 days $(p=0.004)$ with daily sedative interruption. Length of stay in the ICU was also significantly reduced. Additional information was reported in subsequent publications (Kress JP, Pohlman AS, Hall JB. Effects of sedative interruption in critically ill, mechanically ventilated patients receiving midazolam or propofol. J Clin Outcomes Manage 2001;8:33-9; and Kress JP, Gelbach B, Lacy M, et al. The long-term psychological effects of daily sedative interruption on critically ill patients. Am J Resp Crit Care Med 2003;168:1457-61). (Class I)

\section{Toxicology}

Mokhlesi B, Leikin JB, Murray P, Corbridge TC. Adult toxicology in critical care. Part I. General approach to the intoxicated patient. Chest 2003;123:577-92.

Mokhlesi B, Leikin JB, Murray P, Corbridge TC. Adult toxicology in critical care. Part II. Specific poisonings. Chest 2003;123:897-922.

This two-part series provides a comprehensive review of the evaluation, treatment, and outcome of common overdoses and intoxications from the perspective of the critical care practitioner. The first review focuses on the general management of the intoxicated patient, including physical examination and laboratory findings of common toxidromes, nonspecific supportive therapies, and detoxification. The second review discusses the management of specific intoxicants and poisons.

Zimmerman JL. Poisonings and overdoses in the intensive care unit: general and specific management issues. Crit Care Med 2003;31:2794-801.

This article provides a concise and well-written review of current strategies for management of common overdoses and poisonings in the critical care setting. Gastrointestinal decontamination and methods for enhancing elimination of the toxin are covered, and brief overviews are provided for the most common poisonings encountered in the ICU.

\section{Vasoactive Agents}

Hollenberg SM, Ahrens TS, Annan D, et al. Practice parameters for hemodynamic support of sepsis in adult patients: 2004 update. Crit Care Med 2004;32:1928-48.

This recent article is an evidence-based review by the American College of Critical Care Medicine of the literature related to hemodynamic support in patients with sepsis. Specific recommendations are provided for monitoring parameters and end points for therapy. Areas discussed include fluid resuscitation, vasopressor therapy, and inotropic therapy for adult patients with sepsis.

Dellinger RP. Cardiovascular management of septic shock. Crit Care Med 2003;31:946-55.

This concise, well-written review provides an overview of the management of septic shock. Principles of fluid resuscitation, vasopressor and inotropic drug treatment, and the role of vasopressin are covered. A one-page flow diagram of management decisions based on hemodynamic and clinical response is also provided.

Dünser MW, Mayr AJ, Ulmer H, et al. Arginine vasopressin in advanced vasodilatory shock: a prospective, randomized, controlled study. Circulation 2003;107:2313-19.

The increased use of vasopressin in the management of vasodilatory shock is based primarily on small case series, case reports, and very small prospective studies. This study is the largest prospective, randomized, controlled study of vasopressin published to date. Forty-eight patients with vasodilatory shock were randomized to receive arginine vasopressin at 4 $\mathrm{U} / \mathrm{hour}(0.067 \mathrm{U} / \mathrm{min})$ in addition to norepinephrine or continued norepinephrine therapy. The vasodilatory shock in all patients was due to postcardiotomy syndrome (41.6\%), systemic inflammatory response syndrome (29.2\%), or sepsis $(29.2 \%)$. In addition, patients remained hypotensive (mean arterial pressure $<70 \mathrm{~mm}$ $\mathrm{Hg}$ ) despite adequate fluid resuscitation and required norepinephrine administered at more than $0.5 \mu \mathrm{g} / \mathrm{kg} / \mathrm{minute}$. In the arginine vasopressin group, heart rate decreased significantly; mean arterial pressure increased and remained significantly higher; and cardiac index, stroke volume index, and left ventricular stroke work index were increased compared with the norepinephrine group. Norepinephrine requirements were significantly lower in the arginine vasopressin group. New-onset tachycardic atrial fibrillation occurred in two $(8.3 \%)$ patients in the arginine vasopressin group, compared with 14 (54.3\%) patients in the norepinephrine group $(\mathrm{p}<0.001)$. Regional partial pressure of carbon dioxide $\left(\mathrm{PCO}_{2}\right)$ tension and $\mathrm{PCO}_{2}$ gap, as measured by gastric tonometry, were significantly 
lower in the arginine vasopressin group. This suggests improved gastrointestinal perfusion in the intervention group. Mortality in the ICU was $70 \%$ in both study groups. Overall, arginine vasopressin was safe and effective for management of norepinephrine-dependent vasodilatory shock and led to reduced norepinephrine dosage requirements, improved global and regional hemodynamics, and fewer tachyarrhythmias. (Class I)

Holmes CL, Walley KR. Bad medicine: low-dose dopamine in the ICU. Chest 2003;123:1266-75.

The authors reviewed the 30-year history of low-dose dopamine treatment in the ICU. Based on the collective evidence, they concluded that this therapy does not have a beneficial effect in critically ill patients with oliguria. In addition, substantial evidence indicates that low-dose dopamine may have significant detrimental effects. The authors concluded that there is no justification for the use of low-dose dopamine in treating critically ill patients.

Martin C, Viviand X, Leone M, Thirion X. Effect of norepinephrine on the outcome of septic shock. Crit Care Med 2000;28:2758-65.

This prospective, cohort, observational study was designed to identify factors associated with outcome in 97 patients treated for septic shock. Nineteen clinical, biologic, and hemodynamic variables were collected during the first 48-72 hours of treatment. Stepwise logistic regression analysis was used to identify variables that were independently and significantly associated with outcome. The primary outcome variable was hospital mortality, which was $73 \%$ in this cohort. Five factors were significantly associated with outcome. Lactic acidosis, multiple organ failure, pneumonia, and oliguria were associated with an increased risk of death, and norepinephrine as a component of hemodynamic management was associated with reduced risk of death (relative risk ratio $0.68,95 \%$ CI $0.54-0.87$ ) when compared with high-dose dopamine or epinephrine. Currently, no mortality outcome data from prospective randomized trials evaluate the hemodynamic management of septic shock. This observational study is the only study reporting that mortality outcome may be affected by the choice of vasopressors. The study was limited by its observational design and relatively small sample. (Class II)

\section{Economic Benefits of Intensive Care Unit Pharmacy Services}

Krupicka MI, Batton SL, Sonnenthal K, Goldstein B. Impact of a pediatric clinical pharmacist in the pediatric intensive care unit. Crit Care Med 2002;30:919-21.

Gandhi PJ, Smith BS, Tataronis GR, et al. Impact of a pharmacist on drug costs in a coronary care unit. Am J Health-Syst Pharm 2001;58:497-503.

Leape LL, Cullen DJ, Clapp MD, et al. Pharmacist participation on physician rounds and adverse drug events in the intensive care unit. JAMA 1999;282:267-70.

White CM, Chow MS. Cost impact and clinical benefits of focused rounding in the cardiovascular intensive care unit. Hosp Pharm 1998;33:419-23.

Baldinder SL, Chow MS, Gannon RH, et al. Cost savings from having a clinical pharmacist work part time in a medical intensive care unit. Am J Health-Syst Pharm 1997;54:2811-14.

Devlin JW, Holbrook AM, Fuller HD. The effect of ICU sedation guidelines and pharmacist interventions on clinical outcome and drug costs. Ann Pharmacother 1997;31:689-95.

Montazeri M, Cook DJ. Impact of a clinical pharmacist in a multidisciplinary intensive care unit. Crit Care Med 1994;22:1044-8.

Chuang LC, Sutton JD, Henderson GT. Impact of a clinical pharmacist on cost saving and cost avoidance in drug therapy in an intensive care unit. Hosp Pharm 1994;29:215-21.

Rosenbaum CL, Fant WK, Miyagawa CI, Armistead JA. Inability to justify a part-time clinical pharmacist in a community hospital intensive care unit. Am J Health-Syst Pharm 1991;48:2154-7.

Katona BG, Ayd PR, Walters JK, Caspi M, Finkelstein BW. Effect of a pharmacist's and a nurse's interventions on cost of drug therapy in a medical intensive care unit. Am J Hosp Pharm 1989;46:1179-82.

Bearce WC, Willey GA, Fox RL, Coleman LT. Documentation of clinical interactions: quality of care issues and economic considerations in critical care pharmacy. Hosp Pharm 1988;23: 883-90. 
Dasta JF, Armstrong DK. Pharmacoeconomic impact of critically ill surgical patients. Drug Intell Clin Pharm 1988;22:994-8.

Peterson CD, Lake KD. Reducing prophylactic antibiotic costs in cardiovascular surgery: the role of the clinical pharmacist. Drug Intell Clin Pharm 1986;20:134-7.

Miyagawa CI, Rivera JO. Effect of pharmacist interventions on drug therapy costs in a surgical intensive care unit. Am J Hosp Pharm 1986;43:3008-13.

Herfindal ET, Bernstein LR, Kishi DT. Impact of clinical pharmacy services on prescribing on a cardiothoracic-vascular surgical unit. Drug Intell Clin Pharm 1985;19:440-4.

\section{Medication Errors and Adverse Drug Events in} the Intensive Care Unit

Osmon S, Harris CB, Dunagan C, Prentice D, Fraster VJ, Kollef MH. Reporting of medication errors: an intensive care unit experience. Crit Care Med 2004;32:727-33.

Vargas E, Terleira A, Hernando F, et al. Effect of adverse drug reactions on length of stay in surgical intensive care units. Crit Care Med 2003;31:694-8.

van den Bemt PM, Fijn R, van der Voort PH, Gossen AA, Egberts TC, Brouwers JR. Frequency and determinants of drug administration errors in the intensive care unit. Crit Care Med 2002;30:846-50.

Calabrese AD, Erstad BL, Brandl K, Barletta JF, Kane SL, Sherman DS. Medication administration errors in adult patients in the ICU. Intensive Care Med 2001;27:1592-8.

Flaatten $\mathrm{H}$, Hevroy $\mathrm{O}$. Errors in the intensive care unit (ICU). Acta Anaesthesiol Scand 1999;43:614-17.

Tissot E, Cornette C, Demoly P, Jacquet M,
Barale F, Capellier G. Medication errors at the administration stage in an intensive care unit. Intensive Care Med 1999;25:353-9.

Leape LL, Cullen DJ, Clapp MD, et al. Pharmacist participation on physician rounds and adverse drug events in the intensive care unit. JAMA 1999;282:267-70.

Vargas E, Simon J, Puerro M, et al. Effect of adverse drug reactions on length of stay in intensive care units. Clin Drug Invest 1998;15: 353-60.

Schneider MP, Cotting J, Pannatier A. Evaluation of nurses' errors associated in the preparation and administration of medication in a pediatric intensive care unit. Pharm World Sci 1998;20:178-82.

Cullen DJ, Sweitzer BJ, Bates DW, Burdick E, Edmondson A, Leape LL. Preventable adverse drug events in hospitalized patients: a comparative study of intensive care and general care units. Crit Care Med 1997;25:1289-97.

Donchin Y, Gopher D, Olin M, et al. A look into the nature and causes of human errors in the intensive care unit. Crit Care Med 1995;23: 294-300.

Girotti MJ, Garrick C, Tierney MG, et al. Medication administration errors in an adult intensive care unit. Heart Lung 1987;16:449-53.

Tisdale JE. Justifying a pediatric critical-care satellite pharmacy by medication-error reporting. Am J Hosp Pharm 1986;43:368-71.

Abramson NS, Wald KS, Grenvik ANA, Robinson D, Snyder JV. Adverse occurrences in intensive care units. JAMA 1980;244:1582-4.

\section{Acknowledgment}

The authors acknowledge the contributions of Jamie L. Nelsen, Pharm.D., to this project. 